\title{
Overview on low temperature co-fired ceramic sensors
}

\author{
Dominik Jurków ${ }^{1}$, Thomas Maeder ${ }^{2}$, Arkadiusz Dąbrowski ${ }^{1}$, Marina Santo Zarnik ${ }^{3}$, Darko \\ Belavič ${ }^{3}$, Heike Bartsch ${ }^{4}$, Jens Müller ${ }^{4}$, \\ 1) Wroclaw University of Technology, Faculty of Microsystem Electronics and Photonics, Wybrzeze Wyspianskiego 27, 50-370 \\ Wrockaw, Poland. \\ 2) Laboratoire de Production Microtechnique, Ecole Polytechnique Fédérale de Lausanne, Station 17, CH-1015 Lausanne, \\ Switzerland. \\ 3) Jožef Stefan Institute, Jamova 39, 1000 Ljubljana, Slovenia. \\ 4) Technische Universität Ilmenau, IMN MacroNano, Gustav-Kirchhoff-Str. 7, 98693 Ilmenau, Germany.
}

Version of record: Sensors and Actuators, XXXX

http://hdl.handle.net/XXXXX

\begin{abstract}
Low Temperature Co-fired Ceramics (LTCC) is one of the microelectronic techniques. This technology was initially developed as an alternative to Printed Circuit Boards (PCB) and classical thick-film technology, and it has found application in the fabrication of multilayer ceramic boards for electronic devices. Fast and wide development of this technology permitted the fabrication of 3D mechanical structures and integration with various different processes. Thanks to this, LTCC has found application in the manufacturing of various microelectronic devices. This paper presents an overview on LTCC technology and gives a detailed summary on physical quantity sensors fabricated using LTCC technique.
\end{abstract}

Keywords: LTCC, sensor, ceramics

\section{Contents}

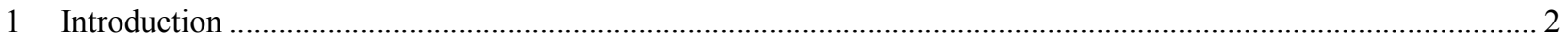

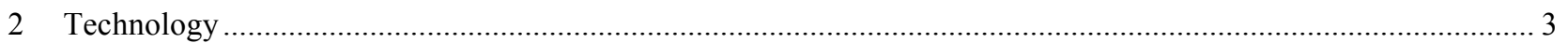

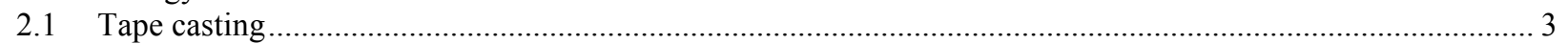

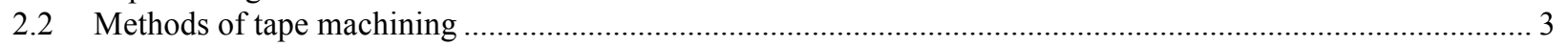

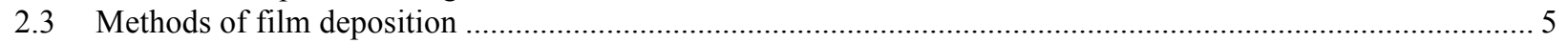

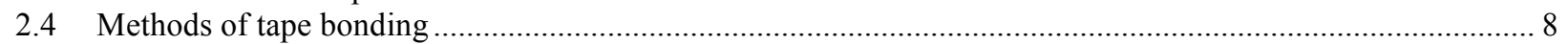

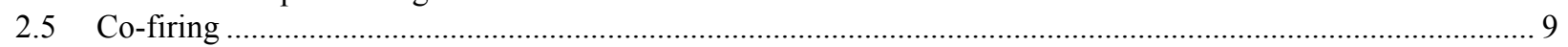

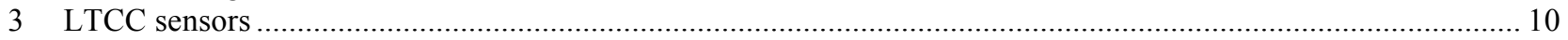

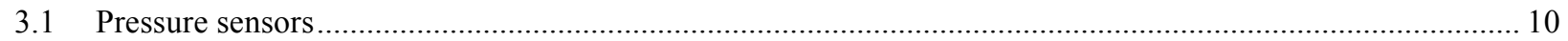

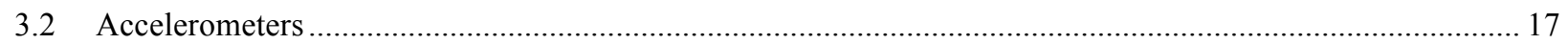

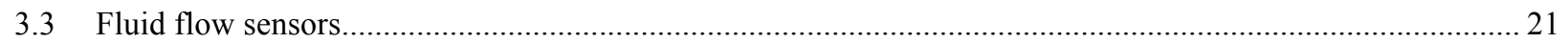

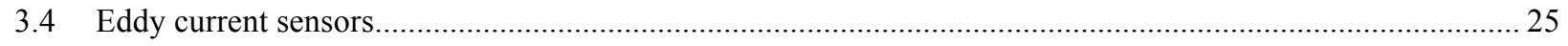

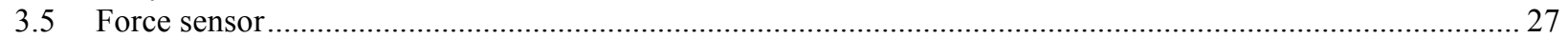

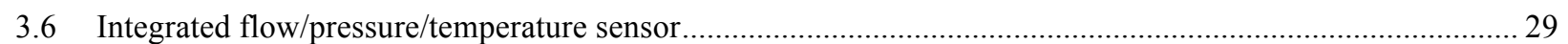

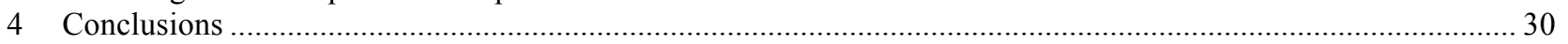

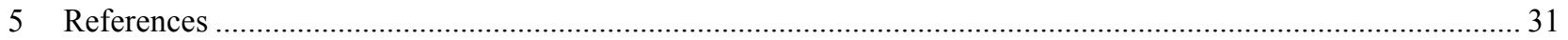

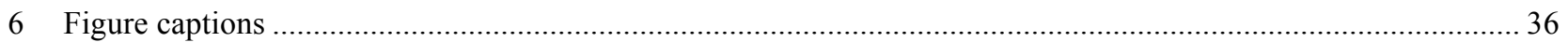

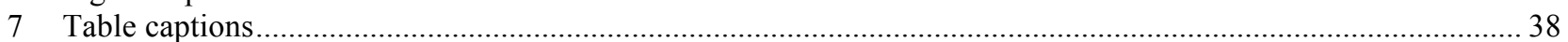

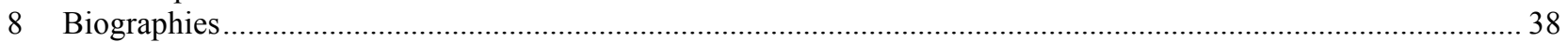




\section{Introduction}

Low Temperature Co-fired Ceramic (LTCC) technology is one of the microelectronic techniques [1,2], which was initially suited for the fabrication of multilayer electronic substrates and RF applications [3-6]. The technology bases on green (unfired) ceramic tapes, which are a composite of organic material, glass frit and ceramic powder. The glass frits are added in order to lower the sintering temperature of the ceramics below the melting point of the electrode material. However, an addition of glass frit degrades the dielectric as well as mechanical properties. Therefore, glass-free LTCC tapes with excellent dielectric properties have been reported recently [7]. However, glass-free LTCC tapes may not be available commercially or appropriate for all applications. LTCC technology makes it possible to process each of the tapes (layers) separately e.g. deposit onto them conductive paths, resistors, dielectrics, $[1,2]$ machine channels, chambers [8] etc., and then bond single tapes together [9]. The possibility of the fabrication of electric vias between layers permits the manufacturing of multilayer electric boards and mechanical structures. After bonding of the tapes (lamination), the green body is fired in a furnace at peak temperature lower than $900^{\circ} \mathrm{C}$, which ensures compatibility with relatively low-cost Ag tracks $[1,10]$. During this process, organic material is first driven off during the debinding phase, followed by sintering, aided by flow of the glass phase. The inorganic fraction densifies due to several sintering mechanisms, which depend on the particular composition of the compound. These sintering mechanisms are explained in [11]. The LTCC technology enables the fabrication of multilayer structures having significantly higher thermal conductivity and better chemical and humidity resistance in comparison to Printed Circuit Boards (PCB). Due to good mechanical and electrical properties of the LTCC as well as to its compatibility with thick film technology and possibility of an integration of both mechanical and electrical components with ceramic chips, LTCC could spread to other potential applications. One of the most promising directions of technology development are ceramic sensors integrated with housing [12]. Such sensors can work at harsh environments, e.g. at high temperatures or humidity.

Among all designed and fabricated LTCC sensors, the simplest are strain gauge (deflection) [13], temperature [14] and proximity sensors [2,15]. Beside of these simplest examples, pressure sensors are also popular [16-20]. The high piezoresistive effect seen in thick-film resistors enables the fabrication of LTCC piezoresistive force sensors [20] or uniaxial accelerometers [21]. The possibility of an integration with LTCC of both electrical components and fluidic channels permits the manufacturing of fluid flow sensors $[20,22]$. The LTCC technique enables also the possibility of moisture sensors manufacturing $[23,24]$. The progress in LTCC sensors area is enhanced by a development of other techniques compatible with LTCC e.g. integrated transparent windows [25,26], LTCC surface modifications [27-28], PDMS bonding [29], etc. Such additional methods are essential in the fabrication of biologically and chemically oriented sensors/microsystems [30-34].

The goal of this paper is to present some basic information about LTCC technology, to highlight the most critical LTCC process stages and to make an overview on novel LTCC sensors which were developed by research from following European teams: Wroclaw University of Technology (Poland), Technische Universität Ilmenau (Germany), École Polytechnique Fédérale de Lausanne (Switzerland) and Jožef Stefan Institute (Slovenia). It summarizes thus the current State of the Art in the field of Low Temperature Cofired Ceramic sensors. 


\section{Technology}

\subsection{Tape casting}

The first step in the LTCC process chain is the tape casting [1,2]. This process consists of two main parts: a preparation of a slurry and a tape casting process of this slurry onto a carrier film. The slurry is a mixture of ceramic particles, glass phase, binder, plasticiser, solvent and dispersant. The ceramic particles are a main component, which affects the properties of the final (fired) structure. A glass frit permits the decrease of peak firing temperature of LTCC below $900 \mathrm{oC}$ and is also present in final structure. Hence, it also affects the properties of the fired structure. The organics (binder, dispersants, solvents, plasticiser) are completely driven off before the densification of the inorganic fraction starts. Therefore, they define the properties of unfired ceramics (green) and their proper composition enables the easiness of a green tape cutting and lamination.

The tape casting phase principle is presented in Fig. 1. The slurry is put in a container with a small gap, through which a slurry is tape casted onto a moving carrier film. The height of the gap is fixed by a position of a doctor blade. Then cast (wet) tape is dried by hot air and rolled onto a final roller. The thickness of wet tape starts from $20 \mu \mathrm{m}$ and it depends mainly on slurry density, tape casting speed and gap dimensions. Dried films have a thickness of $10 \mu \mathrm{m}$ or more. The properties of fired ceramics are mainly designed on a slurry preparation stage. It is worth of noticed that tapes with significantly different properties can be fabricated using tape casting technique [35-39].

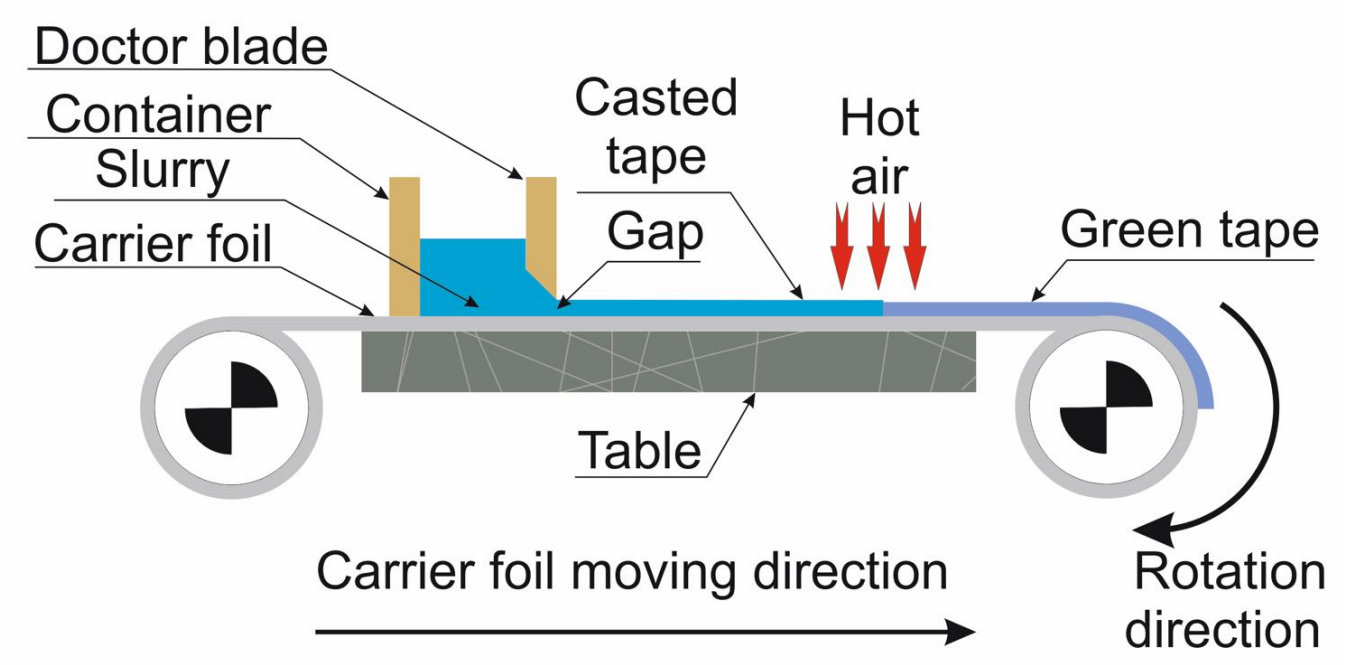

Fig. 1. Tape casting process principle

\subsection{Methods of tape machining}

The possibility of the fabrication of various mechanical structures using LTCC tapes is one of the biggest advantages of this technology, which is the main reason that LTCC can be utilized widely in the manufacturing of sensors. There are four main groups of the LTCC machining methods: punching [40-43], laser cutting [44-49], milling [2,50] and embossing [51-54]. The most widely used are punching and laser cutting. Both these techniques enable the fabrication of structures through LTCC tape. Hence, they are used for the machining of single tapes. In general, the quality of punched holes is better than that of laser drilled ones. Therefore, punching is widely used for the fabrication of vias which permits the electrical contact between circuits placed on different LTCC layers. On the other hand, laser cutting is much more flexible and is very useful in the prototyping and in the manufacturing of complex mechanical shapes. Moreover, 
laser also can be used for an engraving of shapes on surfaces of both single and laminated tapes. The next benefit of laser is the fact that tool wear does not play any role in the process, in contradiction to punching and milling. However, laser cutting depends significantly on laser wavelength and on wavelength absorption of the machined material.

The typical embossing process is useful for the patterning of complex and irregular shapes, because the structure depth is independent from the tape thickness. Hence, the embossing process is used for the definition of fine fluidic channels and commercially in the fabrication of hollows in LTCC for the forming of plasma chambers in a pitched PDP back panels for flat screens [55]. A comprehensive description of the micro forming process is given in [52]. The process allows higher degree of freedom for the design of real 3D ceramic multilayer and finer structure dimensions. Additionally, embossing of complex geometries overcomes two main obstacles of laser cutting: there are no combustion residues and heat-affected zones which may result in cracks, and geometries such as spirals can be generated without limitations. These advantages must be assessed for each application, taking higher costs for embossing tools and additional equipment into account. The LTCC process flow which includes the embossing step is depicted in Fig. 2a. The necessary embossing pressure is typically applied with a uniaxial press and the embossing tool is optically aligned by means of a camera system. The embossing process itself is influenced by the applied pressure, dwell time, embossing temperature and friction conditions at the interface between green ceramic tape and embossing tool [56]. The optimum ratio between the mould depth and tape thickness amounts to 0.3 for the forming of such structures at $60^{\circ} \mathrm{C}$ in DP 951. Lateral dimensions are moulded with high accuracy and the lateral shrinkage does not exceed typical tolerances of multilayer ceramic processing [56]. Fig. $2 \mathrm{~b}$ visualizes forming and recovery effects, for example of an embossed $50 \mu \mathrm{m}$ fine-line structure in DP 951 green tape.

The last technique of tape machining is milling. The method is used commercially to create half-open chambers or through laminate holes after lamination of LTCC sheets. The milling process has to be conducted very precisely, lest some deformation of LTCC plastic organics occur. This technique is also much less useful in the manufacturing of shapes in very thin structures (below $100 \mu \mathrm{m}$ ).

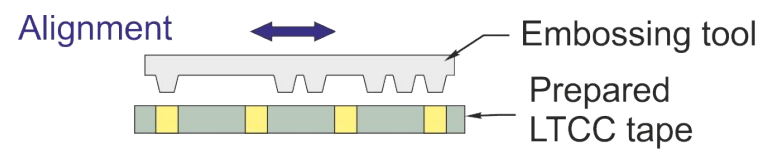

Embossing

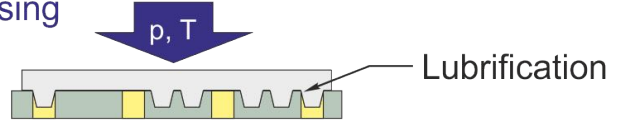

Filling of conductor paths

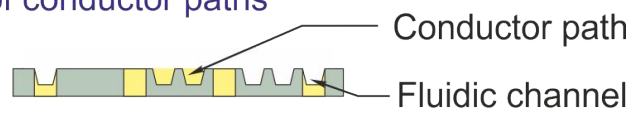

Stacking and lamination

a)

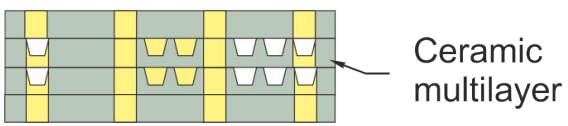

b)

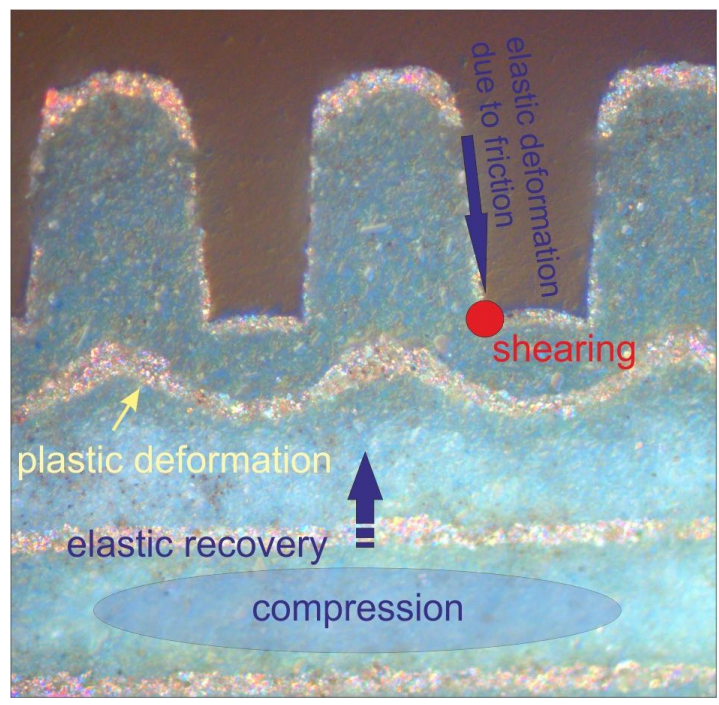

Fig. 2. Embossing, a) process flow for embossing of green LTCC tapes, b) major effects on the embossing result for fine line forming 


\subsection{Methods of film deposition}

The compatibility of the LTCC technique with various deposition techniques permits the integration of a wide range of functional layers into LTCC multilayer. The most promising methods will be described in this subchapter.

\subsubsection{Ink preparation}

Inks are mainly applied onto LTCC by usual thick-film methods, i.e. screen and stencil printing, which require them to be formulated as pastes. Alternative methods are aerosol [57] and inkjet [58] printing. This section mainly concentrates ink formulation for co-firing with

LTCC, and especially on the organic vehicle and the issues often resulting from its interaction with unfired LTCC: wetting, ingress within the porosity of the tape, and potential destruction of the tape by the ink solvent [59].

A thick-film paste usually comprises an inorganic filler (often a mixture of powders), dispersed within an organic printing vehicle, which serves to impart the correct thixotropic rheology for screen/stencil printing [60]. This vehicle basically consists of two components: the solvent (or solvent mix) and the binder phase. The solvent dissolves the binder, making the vehicle a viscous fluid that combines with the inorganic filler to yield the right thixotropic rheology for printing. Upon drying and solvent evaporation, the binder phase keeps the mineral particles together for the subsequent handling and lamination operations.

There are several main potential issues for co-fired thick-film pastes on LTCC:

1. Possible degradation of the LTCC binder by the vehicle, especially the solvent(s)

2. Stresses that can cause warping or cracking of the LTCC tape

3. Cracking of the layers by deformations arising upon lamination

4. Possible incompatibility in debinding behaviour

5. Firing shrinkage mismatch

6. Chemical interactions upon firing

An exemplary, very standard thick-film vehicle composition is (by weight) $8 \%$ long-chain ethylcellulose (EC) polymer binder, dissolved in 46\% terpineol / 46\% dibutyl carbitol (DBC) solvent / co-solvent mix [61]. As EC is rather hard, a plasticiser is required, and 3\% acetyl tributyl citrate (ATBC) is used here for this purpose. Additional components (dispersants, extenders, waxes, stabilisers) may be added to the vehicle to tune the paste properties.

Although such a vehicle is well-suited to printing small amounts of ink on thick LTCC tapes, the aggressivity of its solvent and co-solvent to tape binders [59] will result in severe tape

degradation when printing thick ink layers, such as sacrificial inks $[62,63]$ and especially onto thin tapes. This issue may be addressed using a binder / solvent chemistry with solubility parameters [59] more different from that of the LTCC tape binder, as demonstrated using hydrophilic binders such as polyvinyl alcohol (PVA) [62] and polyvinyl pyrrolidone (PVP) [63], the latter, as EC, also requiring a plasticiser (see Fig. 3.).

After drying, a typical ink will be quite porous, as only the small amount of the binder phase $(8 \%=$ binder + plasticiser in the abovementioned example) will not be able to close the pores between the mineral powder compact. This is desirable in general, as it facilitates burnout upon firing; large binder amounts, in combination with a binder having a high decomposition temperature such as polyvinylpyrrolidone (PVP), can prevent venting of gases during debinding, resulting in delamination of structures (see Fig. 4) [63]. Nevertheless, a slightly higher binder and plasticiser amount vs. standard thick-film pastes can be added to avoid cracking during lamination.

Beside considerations regarding the organic vehicle, ink formulation for co-firing with LTCC must take into account both shrinkage matching with the LTCC structure [64] and a higher degree of chemical reaction than when firing on a relatively inert alumina substrate, or even post-firing on LTCC, be it on the surface or within LTCC, which poses an issue for resistors (standard or thermistors), which are very 
sensitive to these interactions [65-67], with buried resistors even sometimes resulting in swelling reactions [67].

Shrinkage matching is especially problematic for thin sensor structures, as attested in Fig. 5 [64]. This issue was here mitigated by minimizing the conductor cross-section, but changing to other materials, or even adding small amounts of oxide powders to retard and decrease sintering can allow a reasonable degree of shrinkage matching [68].
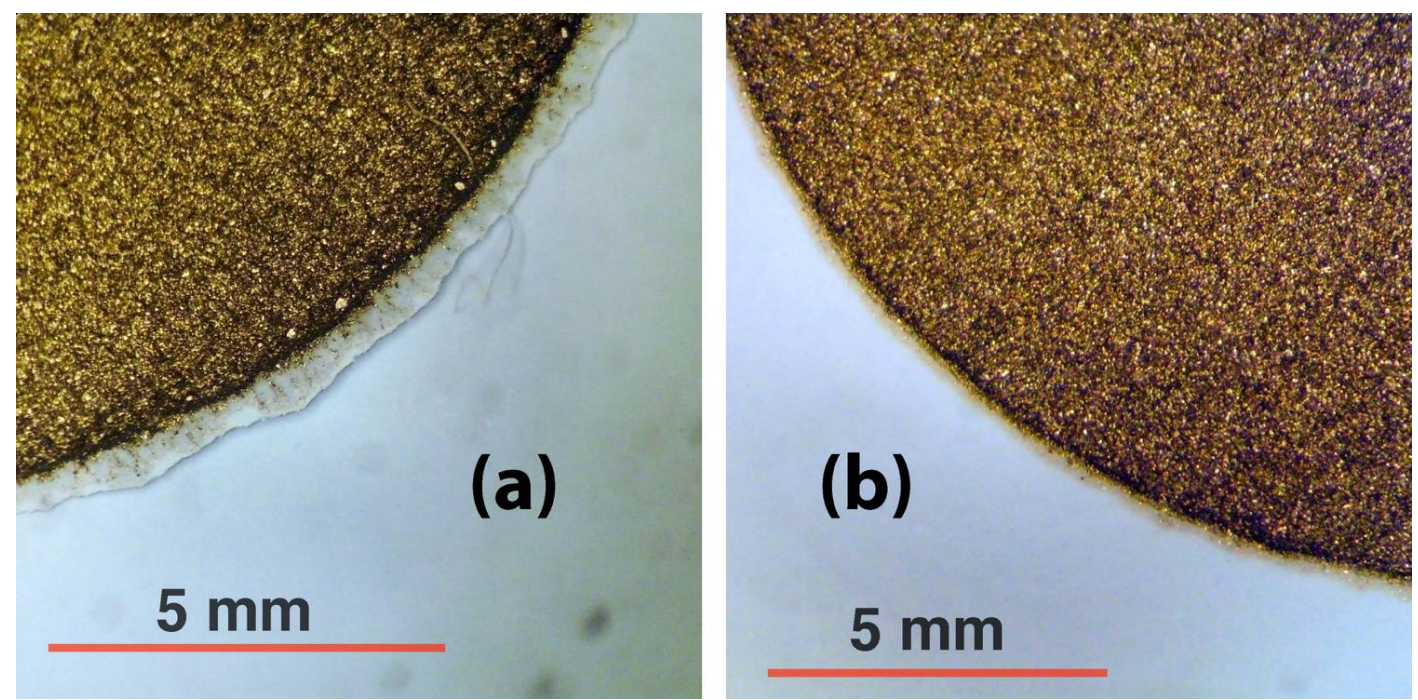

Fig. 3. Effect of plasticiser on PVP-bound sacrificial graphite layer: the stresses in the hard, unplasticised PVP (a) result in cracking of the LTCC tape, while no cracking is observed with glycerol plasticiser (b). Reprinted from [63], with permission from Elsevier (@2012).

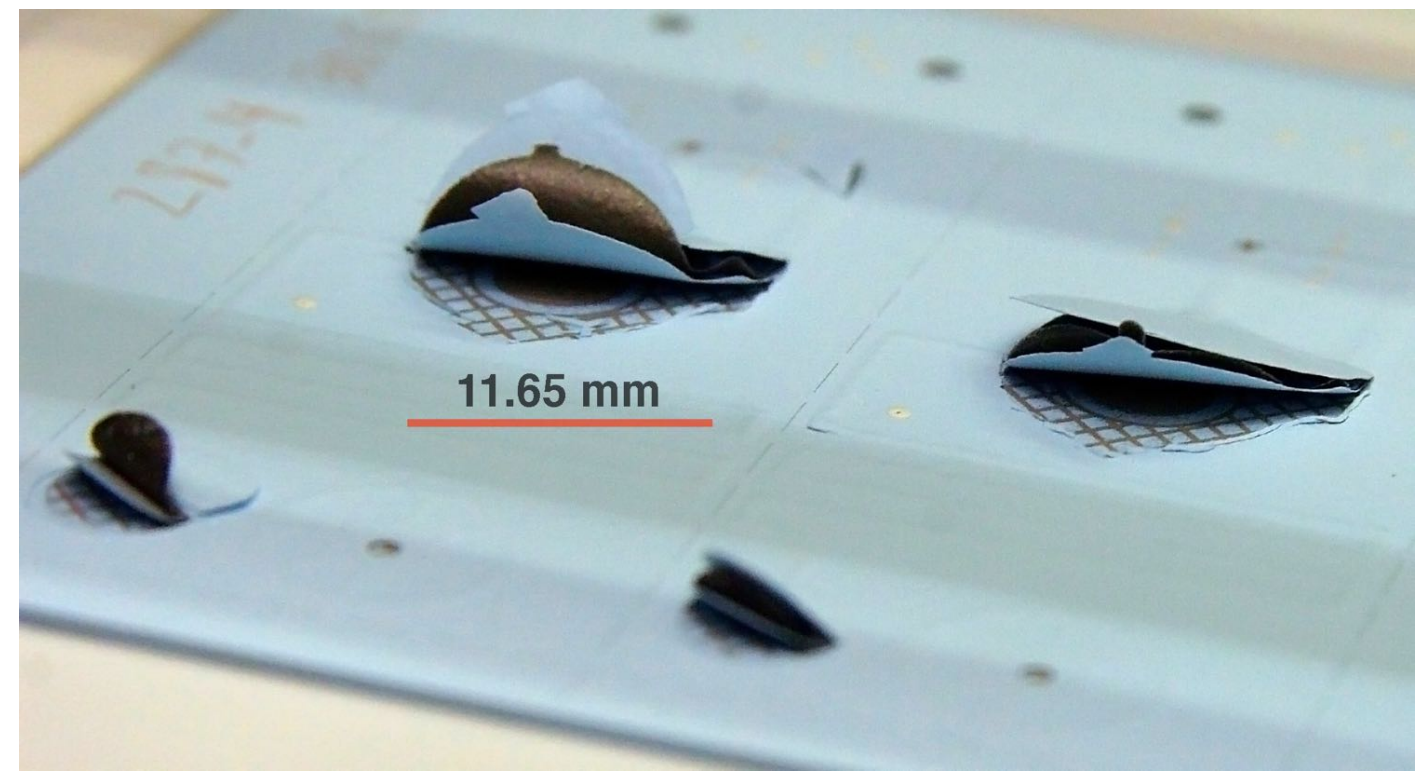

Fig. 4. Delamination of LTCC structures (blue) and sacrificial carbon paste (black) during the debinding step (firing interrupted at $520^{\circ} \mathrm{C}$ ), due to a combination of large amounts of PVP binder and high decomposition temperature thereof blocking gases evolved during debinding. Reprinted from [63], with permission from Elsevier (C2012). 

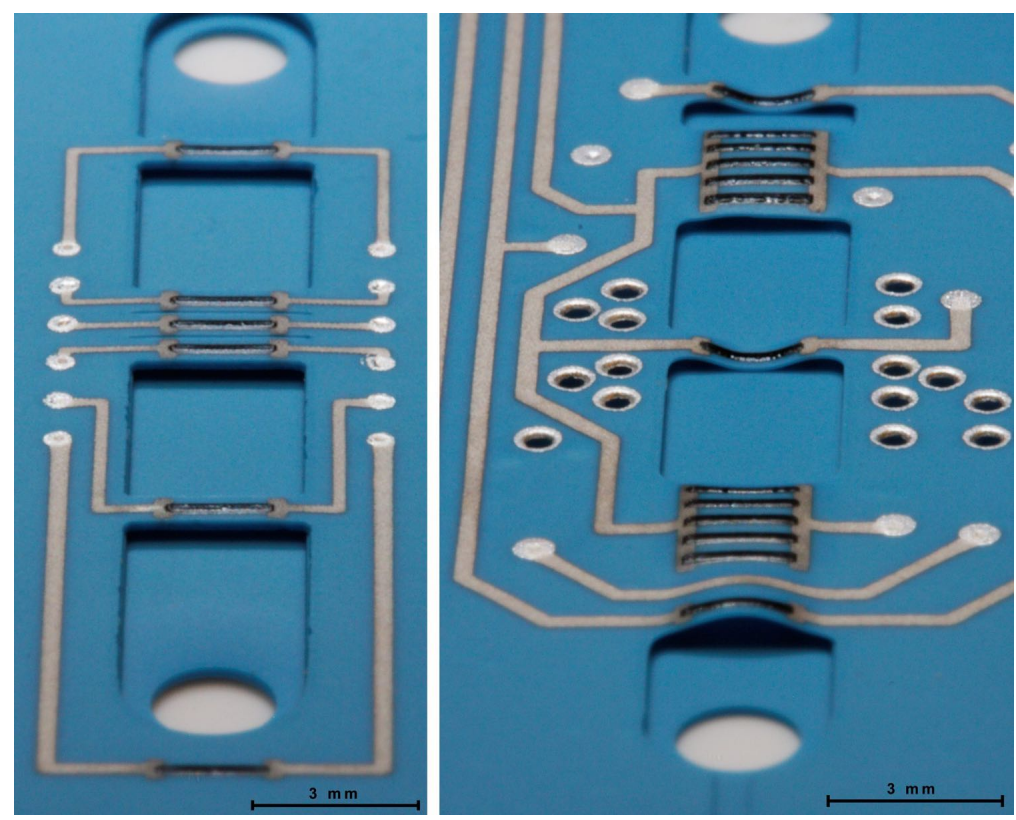

Fig. 5. Deformation of fine LTCC bridges of a flow sensor due to dimensional variations of the Ag-Pd conductor (right), an issue mitigated by using thinner and/or narrower conductor tracks (left). Reprinted from [64].

\subsubsection{Stencil and screen printing}

Both screen and stencil printing are widely known deposition methods in microelectronics [69, 70]. Both techniques are compatible with standard thick-film technology. Traditionally screen printing is used for the deposition of resistor, dielectric, piezoelectric and glass pastes. Meanwhile stencil printing is mainly used for the deposition of solder pastes for the soldering process and for filling of vias. These different areas of applications are caused by slightly different process principles. A main tool of a screen printing process is a screen with mesh. The mesh is covered by photosensitive material in which using UV exposing through a special mask a pattern is fabricated. This pattern (uncovered parts of a screen) can be used for the deposition of very geometrically sophisticated films onto LTCC tapes. The mesh parameters are wire diameter, mesh fineness (number of openings per inch), mesh opening, tensioning [71]. The deposition process can be recognized as being relatively easy. Unfortunately, such assumption can be only made for simple and not demanding patterns. Beside the screen parameters, screen printing quality depends also on process parameters and

rheology of pastes. The most technologically developed screens and proper pastes permit the deposition of conductive paths in a resolution better than $40 \mu \mathrm{m}$ [72], making screen printing competitive even for highdensity hybrid electronics. Stencil printing, in comparison with screen printing, is slightly different. The stencil is a metal sheet with proper thickness, into which the pattern has been (usually) laser cut. Therefore, it is useful for the deposition of relatively simple patterns. On the other hand, the definition of stencil print edges is better in comparison to screen printing, and the process is more robust with respect to paste rheology and process parameter deviations. Hence, a deposition of more repeatable resistors is possible using stencil printing [70]. Moreover, electrical vias in LTCC tapes can be filled better using stencils due to the absence of wires on the whole printing area, i.e. the compromise between resolution and achievable thickness is better for stencils than for screens. Screen and Stencil printing are very well developed and offer very wide range of commercially accessible inks, therefore, these techniques are the most often commercially used. Moreover, both methods are further developed by optimisation of squeegees geometries [73] or by proper development of screens fabrics (e.g. covering them by hydrophobic/hydrophilic solution) [72]. 


\subsubsection{Ink jet}

Compared to stencil or screen printing, inkjet printing does not require a mask, and is therefore especially attractive for rapid prototyping purposes. However, inkjet printing poses challenges on its own, such as sedimentation, compatible particle size, ink rheology and clogging.

Due to the much lower ink viscosity (dependent on printer and nozzle), sedimentation is a much more grave issue than for stencil or screen printing. For conductors, one may use dissolved organometallic molecules to avoid sedimentation entirely. This solution is also potentially applicable for those metals (e.g. $\mathrm{Cu}$ and $\mathrm{Bi}$ ) used for reactive conductor-substrate bonding [74]. Sedimentation is also largely avoided by using nanoparticles $[58,75]$. Using solutions and/or nanoparticles also is compatible with small nozzles, allowing a high printing resolution. The situation, however, is less favourable for materials such as dielectrics, resistors and glass frits, which usually contain coarser materials, especially glass frits. Use of appropriate dispersants can impart reasonable stability to suspension inks made with such coarser powders [76], but resolution will be somewhat limited by the requirement of a wider nozzle (typically at least $50-100 \times$ the particle diameter [77]).

Compared to screen / stencil printing, the shear rate experienced in an inkjet nozzle is very high, which can pose special rheological issues with polymers used as binders or for stabilizing dispersions, such as shear thickening, which may be addressed by tuning the polymer structure, e.g. applying polymer molecules with a star rather than a linear structure [78]. The drying behaviour of the ink is also important: the ink must dry sufficiently fast on the substrate, but this tends to lead to poor quality ("coffee-stain" effect), and fast-drying inks exacerbate nozzle clogging problems. These issues may be mitigated by adding a trailing (slowdrying) solvent, such as glycerol in water [77].

One restriction for inkjet printing is the rather low thickness achievable in a single pass (low volume fraction of active phase and small deposited ink volume), which may be impractical for materials such as dielectrics, or even be insufficient to survive co-firing with LTCC tape [58]. In this case, the related aerosol printing method may be more advantageous [57]. Promising results have also been achieved by printing hot-melt inks (which solidify quasi- instantly upon impinging onto the substrate) as masks for other processes such as electrodeposition [79].

\subsubsection{Sol-gel}

A sol-gel is an another type of material which can be combined with LTCC [80,81]. A sol is achieved in the chemical process of hydrolysis and condensations of metalorganics, e.g. alkoxides or carboxylates [81]. Then it can be deposited onto LTCC using e.g. dip-coating or spin-coating methods. After coating the solvent is driven off from sol and it becomes a gel, which is then sintered in a furnace. Sol-gel method is used e.g. for the fabrication of optical layers onto LTCC, the decreasing of LTCC surface roughness or for the fabrication of sensing layers [80, 81].

\subsection{Methods of tape bonding}

Machined tapes with deposited electrical layers have to be in some way joined (bonded) together. The process is possible because of the fact that the green LTCC tapes consists of organics which exhibit plastic behaviour. There are two main LTCC tape bonding families: thermo-compressive and chemical.

\subsubsection{Thermo-compressive methods}

The lamination is a process which can mainly affect the quality (deformation) of LTCC 3D mechanical structures [82]. The most widely used method for tapes joining is thermo- compression. This bonding mechanism can be modelled as a joining of plastic materials together. Hence, all laminated tapes have to be heated to softening point of organics and the tapes have to be pressed together applying either uniaxial or isostatic pressure. This process is typically carried out above ambient temperature in a range from 70 to 90 ${ }^{\circ} \mathrm{C}$ ) at pressures from 2 to $30 \mathrm{MPa}$ for a 3 to $10 \mathrm{~min}[11,83$ ]. As it was shown in [84], the plastic model does not describe fully the bonding of LTCC. According to [84], the final lamination strength between layers depends on three mechanisms: joining of melted resinous constituents (occurs during lamination), mechanical bonding of unevenness in the joint surface (occurs during lamination), the glass material viscous flow (occurs during firing). The above given model shows clearly that beside the plasticity of organics, also the green tape surface roughness as well as the co-firing process conditions and glass type 
determine the lamination strength. According to this explanation the higher surface roughness the better bonding can be achieved. Beside of positive effect on tapes joining, the viscous flow during co-firing deforms bonded structures. Thermo-compressive lamination can cause structure deformation because of joining tapes at elevated temperature under high pressure. It has been proven that a reduction of lamination pressure is possible [85] and thermo-compressive bonding can be carried out under 0.5 MPa. Such low pressure permits the fabrication of structures with very thin LTCC membranes down to $40 \mu \mathrm{m}$ thickness [85]. We can conclude that thermo- compression is very useful for the lamination of tapes with thick-film components and that it permits bonding of up to 40 layers.

\subsubsection{Thermo-compressive lamination with sacrificial materials}

In some cases, the use of high pressure for thermo-compressive lamination is essential. This might happen if e.g. thick-film materials have been deposited onto LTCC or due to possible overdrying of the tape and to the resulting corrugations. If such tapes have to be bonded together and the final structure shall consists of buried chambers, the lamination can be carried out using additional sacrificial material (fugitive phase) [8688]. The chambers which have to be protected from deformation are completely filled with a fugitive material and then tapes are laminated using typical pressures. Such a sacrificial material protects the chambers from deformation during lamination, and is then completely driven off during debinding. The negative aspect is the resulting elongation of the co-firing process, due to the necessity of ensuring proper conditions for driving off the fugitive phase, in addition to the LTCC binder. This elongation can be avoided if a final structure has only open cavities. In this latter case, such 3D mechanical structures can be protected by rubber-like insert material $[85,89]$, which sustains the structure during lamination and is taken out after it.

\subsubsection{Chemical methods}

Chemical bonding methods are an alternative to thermo-compressive lamination. The first solutions from this group were presented by Roosen et al. [90,91]. The green tapes are temporarily joined together using double side adhesive tape, permanent bonding occurring during co-firing. The mechanism of this process can be described as follows: the adhesive melts during the initial stage of co-firing and capillary forces draw the tapes together. Then, bonding is achieved by viscous flow of glass. Other chemical lamination methods are very similar to the one described above. The tapes can be temporarily bonded by some adhesives [92-94] or laminated using solvents [95-97]. Chemical bonding is not as universal as the thermocompressive method. The solvents have to be chosen individually to match the different LTCC tapes systems, moreover, the method can affect repeatability of thick-film components [96]. It is also expected that the reliability of vias can be endangered by these lamination techniques.

\subsection{Co-firing}

The final step is co-firing [1]. The process consists of two main parts: debinding and sintering [11]. During debinding organic material is evaporated (e.g. plasticisers) or/and decomposed (e.g. polymers). Green LTCC tapes have some initial porosity after tape casting. This porosity is increased after evaporation of solvents and debinding. It permits the proper evaporation of organics. It must be given sufficient time for the debinding, lest the green body crack or burst due to the pressure of the evolved gases [98]. The debinded body is then heated up to a peak temperature lower than $900 \mathrm{oC}$, which permits compatibility with relatively low-cost Ag tracks [10]. The inorganic fraction densifies due to several sintering mechanisms e.g. glass flow, reactions, crystallization etc. The mechanisms depend on the particular composition of the compound and are explained in detail in [11,99]. 


\section{LTCC sensors}

The sensors can be fabricated using different LTCC systems. The most popular in the last years have been following of them: DuPont 951, DuPont 943, DuPont 9K7, Ferro A6M, ESL 41110-70C , Heraeus CT 2000, Heraeus HL2000, CeramTape GC, Heraeus 800. However, this short list does not show all LTCC systems which were or are available commercially. The properties of these systems can be found in $[1,2,87]$ or in datasheets. The properties of LTCC materials are adapted to different applications. Therefore, the type of the LTCC system affects the sensors parameters. If the devices have to work at higher frequencies, the most suited system for it is DuPont 9K7 (formerly DuPont 943). The dielectric constant and losses are extremely important when devices have to integrate capacitors. Also, other LTCC properties can be important, depending on the application, e.g. thermal conductivity, Poisson ration, Young modulus, etc. Besides the LTCC properties, the compatibility of thick-film pastes and their availability also have to be considered at the design stage.

This chapter aims to present different families and types of LTCC based sensors, which were developed by following European teams: Wroclaw University of Technology (Poland), Technische Universität Ilmenau (Germany), Ecole Polytechnique Fédérale de Lausanne (Switzerland) and Jožef Stefan Institute in cooperation with small research organization HIPOT-RR (Slovenia).

\subsection{Pressure sensors}

\subsubsection{Piezoelectric principle}

Piezoelectric sensors are common in high-pressure measurements. Typically, charge output devices are manufactured, hence only pressure changes can be detected. For medium and low pressure range (10 kPa up to $1 \mathrm{MPa}$ ), thick-film sensors that operate in resonance mode are convenient.

The difficulty in manufacturing of thick-film (and) resonant sensors with desired characteristics is the deterioration of the functional properties of piezoelectric films processed on the rather reactive LTCC substrates. The effective properties of the piezoceramic thick film are generally worse in comparison to the bulk piezoceramics due to the clamping to the substrate, and they depend not only on the material composition, but also on its compatibility with the electrodes and substrate materials and the processing parameters. An extra precaution is needed when designing functional structures for LTCC sensors. Cofiring of piezoceramic films with green LTCC has not been possible and is still a challenge. However, recent literature reports on successful realizations of pressure sensors and actuators on pre-fired LTCC structures as e.g. [101-105].

The schematic presentation of the piezoelectrically driven diaphragm-type sensing structure is presented in Fig. 6. The operating principle is as follows: the sensing diaphragm is driven by the PZT thick-film actuator, using the reverse piezoelectric effect to oscillate in the fundamental oscillating mode, which is modulated by the applied pressure as a function of the changed tensile state. At the same time, the thickfilm actuator on the membrane acts as a sensor utilizing the direct piezoelectric effect. The pressure change can be assessed from the impedance spectra. An example of the sensor realization, in which the resonating sensor structure was inserted in the oscillator circuit's feedback loop, is presented in Fig. 7b. The characteristics of the sensor achieved for an optimized design (Fig. 7a) which was carried out from numerical simulations based feasibility study [101] is presented in Fig. 7c. The characterization and numerical modelling strategy used in these analyses is described in [106]. 


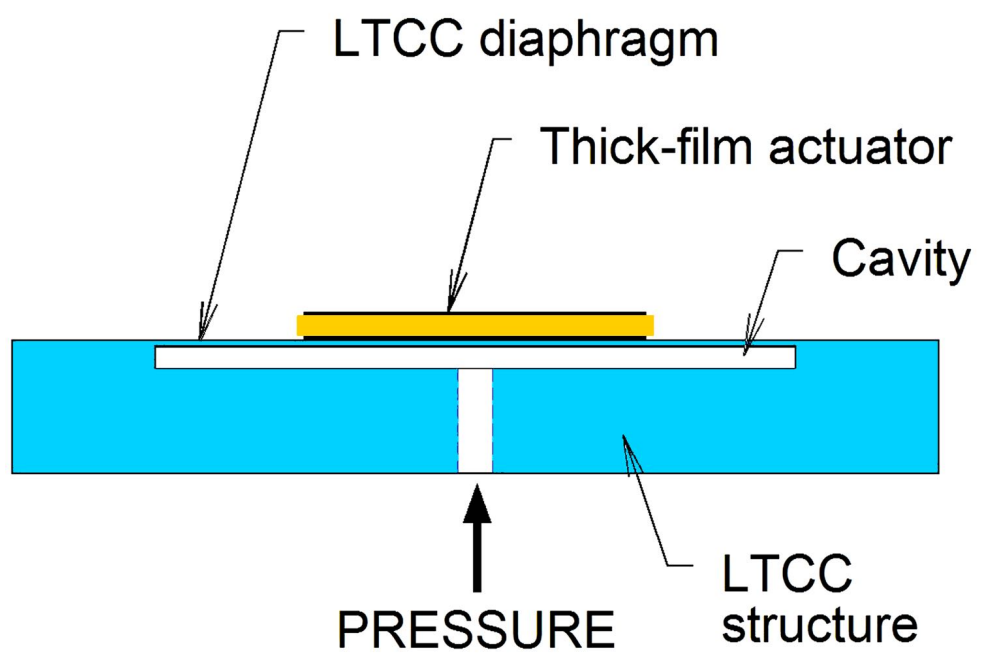

Fig. 6. The scheme of the cross-section of the thick-film actuator/sensor structure on the LTCC membrane (Not to scale)

a)

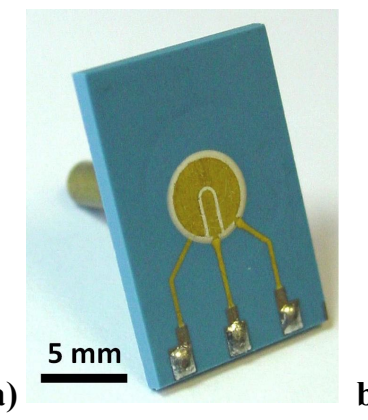

b)

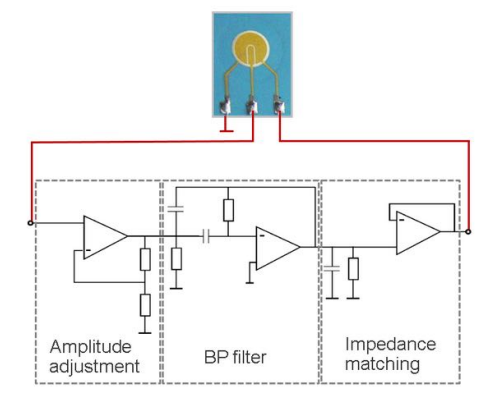

c)

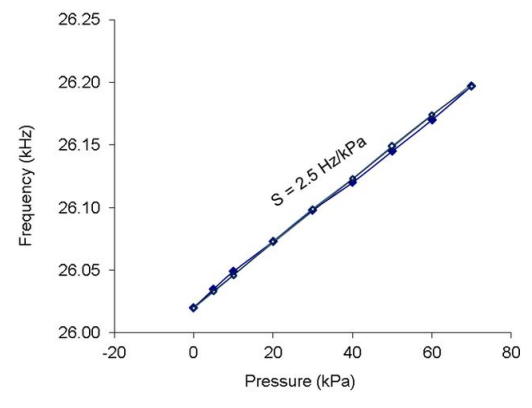

Fig. 7. Piezoelectric resonant pressure sensor a) the prototype, b) the sensor/actuator structure in the oscillator circuit and c) the typical measured characteristic

Beside low-pressure sensing devices, LTCC permits the fabrication of high-pressure sensors as well [107]. The cross section of an exemplary device is presented in Fig. 8a. This sensor is designed as a completely ceramic device, able to withstand pressure up to $10 \mathrm{MPa}$. The benefit of the sensor is utilization of two measuring modes, charge and resonant, which allows measurement of static pressures (resonant mode) as well as pressure changes (charge mode). This dual-mode functionality is made possible by the sensor construction, which consists of two separate planar electrodes in various sensor regions, as presented in $8 \mathrm{~b}$. The larger electrode serves as an exciting electrode, and the smaller ensures feedback for the amplifier in the piezoelectric oscillator circuit. The mode of operation is dependent on the electronic circuit connected to the device - oscillator amplifier or charge amplifier.

The high-pressure sensor was made of two LTCC (Green Tape 951, DuPont) blocks with thickness of about $1.5 \mathrm{~mm}$ and PZT tape (based on Pz27, Meggitt Sensing Systems, Denmark) with thickness of $250 \mu \mathrm{m}$. The LTCC and PZT components were joined together in sintered state using an overglaze (9615, DuPont), assuring proper leak tightness after firing. The manufactured device is presented in Fig. 8c. Its charge response presented in Fig. 9a exhibits nonlinearity in the low pressure range, which is typical for nonpreloaded piezoelectric transducers. The characteristic of the resonant frequency vs. pressure shows nonlinearity for pressure above $4 \mathrm{MPa}$ (Fig. 9b). 


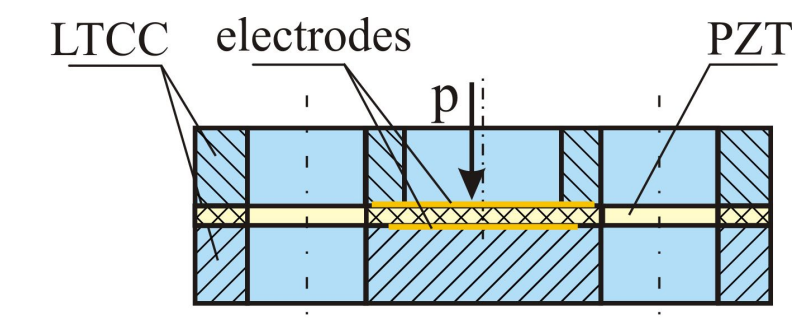

a)

Fig. 8. Piezoelectric pressure sensor in LTCC package, a) cross section of designed sensor, b) bottom electrode on PZT tape, c) fabricated device
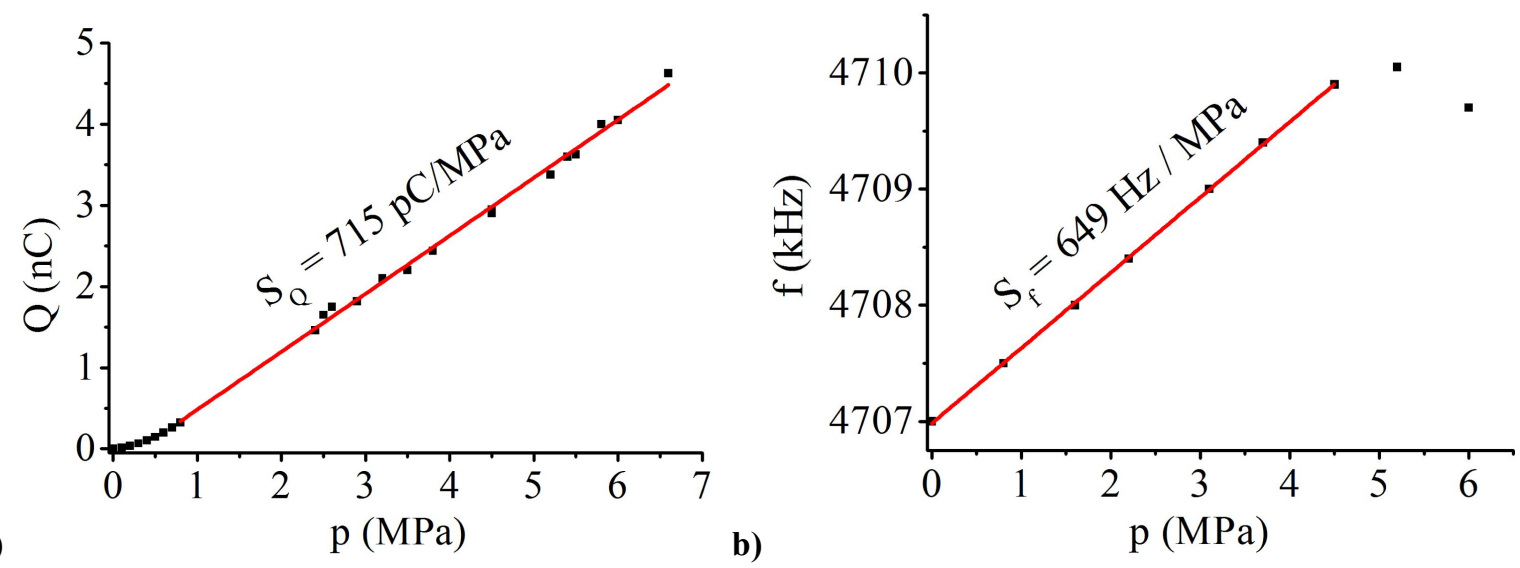

Fig. 9. Results of measurements: a) charge response, b) resonant frequency shift

The other method for piezoelectric pressure detection is the utilization of ultrasonic waves for sensing purposes [108]. The device consists of an LTCC membrane, a layer of the PZT material on its surface and two interdigital transducers (IDTs). The design of the LTCC differential pressure sensor is presented in Fig. 10a. A standard LTCC process was applied for manufacturing of the membrane and two parts of the package. Gold electrodes were screen printed on raw PZT tape and the tape was chemically laminated to the surface of the membrane and then sintered. The fired PZT tape on the LTCC is presented in Fig. 10b. All components were joined together using a sealing glass. The sensor is able to measure differential pressure up to $20 \mathrm{kPa}$ and withstand common pressure up to $500 \mathrm{kPa}$. The final sensor in the package is presented in Fig. 10c. The device was characterized in oscillator mode, where frequency shift was observed during pressure change. Results exhibit good linearity and repeatability, as shown in Fig. 11a and Fig. 11b. Some scatter is a consequence of a large temperature effect, which is equal to $-1.8 \mathrm{kHz} /{ }^{\circ} \mathrm{C}$. The effect requires compensation of thermal drift which is proposed and described in [108]. The presented sensor can be applied for example for the pressure monitoring in ventilation systems, where the temperature is almost constant and can be easily compensated.

a)

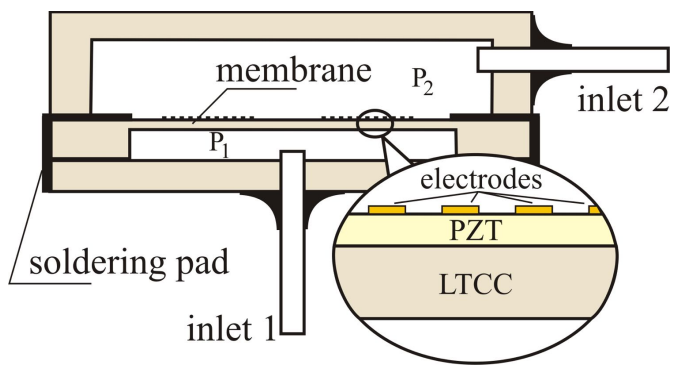

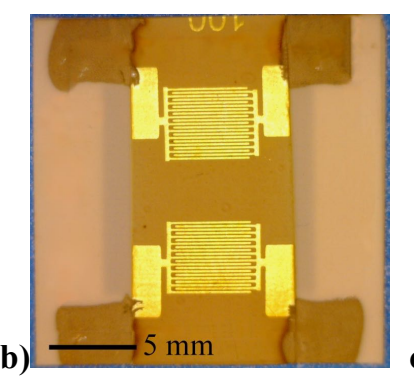

c)

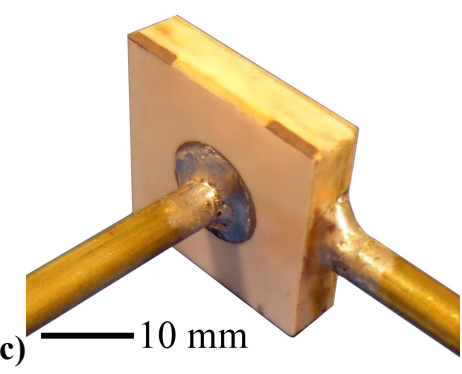

Fig. 10. Design of differential pressure sensor, a) cross section, b) membrane with IDT transducers, c) completely assembled device 

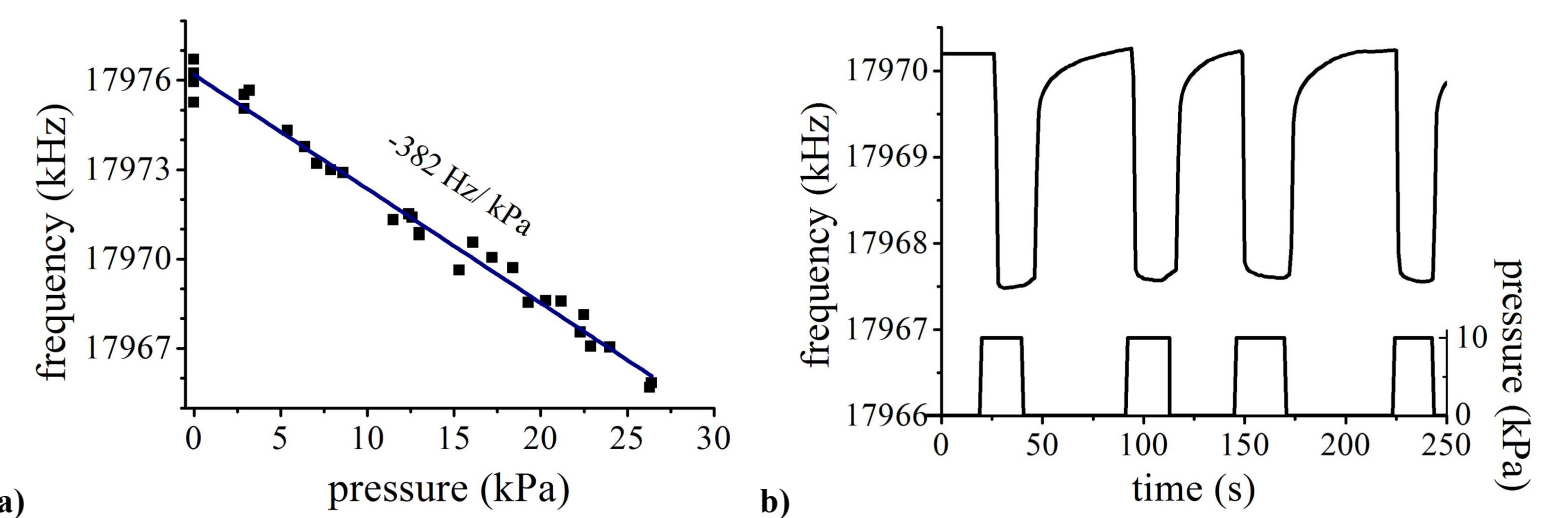

Fig. 11. Results of measurements in oscillator mode: a) static, b) dynamic measurement

\subsubsection{Piezoresistive principle}

A piezoresistive ceramic pressure sensor utilizes the piezoresistive effect, which occur in thick-film resistors that are screen-printed and fired onto the deformable diaphragm [104, 105, 109]. The cross-section of such sensor model, top view of thick-film resistors placement and signal collecting electrical circuit are presented in Fig. 12. The piezoresistive ceramic pressure sensor consists of four thick-film resistors, which act as strain gauges and translate a strain into an electrical signal. The sensitivity of a thick-film resistor to strain is expressed as a gauge factor (GF). The typical resistances of the sensing resistors are about $10 \mathrm{k} \Omega$ and GF are between 10 and 20. The pressure is applied through a brass tube and the diaphragm deforms. The deformation is measured as voltage Vo value (see Fig. 12c). This voltage depends on the resistance of all resistors, meanwhile each single resistor resistance depends on this resistor deformation.

A sufficiently high resolution of the sensor is crucial for precise measurements in any application. The intrinsic resolution of the piezoresistive LTCC pressure sensors is determined by the sensitivity and the electronic noise in the functional thick-film resistors, both depending on the material and the structural properties of the sensing structure. In general, the sensitivity can be increased and the noise level can be reduced for an optimized design and with the additional electronics for the signal processing, but this certainly makes the sensor more expensive. An important finding in this respect was the result of the experimental analysis based on the $1 / \mathrm{f}$ noise measurements [110], which revealed that the intrinsic resolution of the piezoresistive LTCC-based pressure sensor is at least comparable to that of the silicon pressure sensor designed for the same pressure range. Noise measurements were used to evaluate the most appropriate technology and resistive materials for pressure sensor application [111]. Due to lower temperature conductivity in comparison with alumina the warm-up must be taken in account when designing some special applications [112].

a)

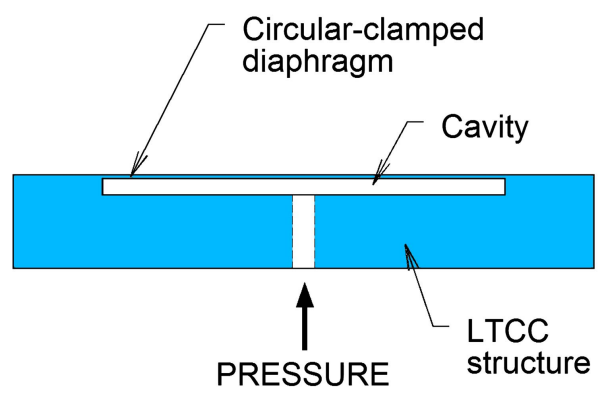

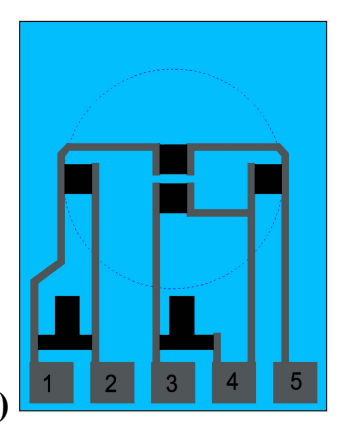

b)

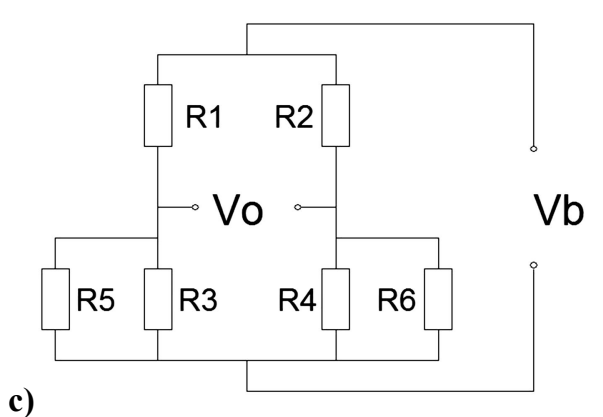

Fig 12. Schematic representation of the sensor (not to scale): a) the cross-section, b) sketch of the top-view and c) the Wheatstone-bridge's connection of the thick-film piezoresistors. 
A further important issue lies in the sensor's long-term stability. The stability studies of the piezoresistive, LTCC-based pressure sensors (one representative is shown in Fig. 13), subjected to functional fatigue tests at normal atmospheric conditions [113] and high humidity conditions [114] revealed the comprehensible vulnerability of the sensor's structure from the point of view of the long-term stability. Nevertheless, the stability of the key characteristics was found to be satisfactory for accurate measurements in a wide range of applications. A recent study of the long-term stability [115] showed that low-frequency noise measurements can reveal uncritical defects and imperfections in the thick-film resistors that cannot be detected by using conventional inspection and standard functional tests. The sensors with such defects are potentially unstable e.g. more sensitive to the pressure cycles, particularly at the pressure overloads. In this way, the noise measurements, which indirectly indicate the potentially unstable sensors, can be used as a successful pre-screening test for a relatively quick assessment of the sensors' long-term stability. The LTCC-based pressure sensor is proven to be appropriate for wet-wet application in water [116].

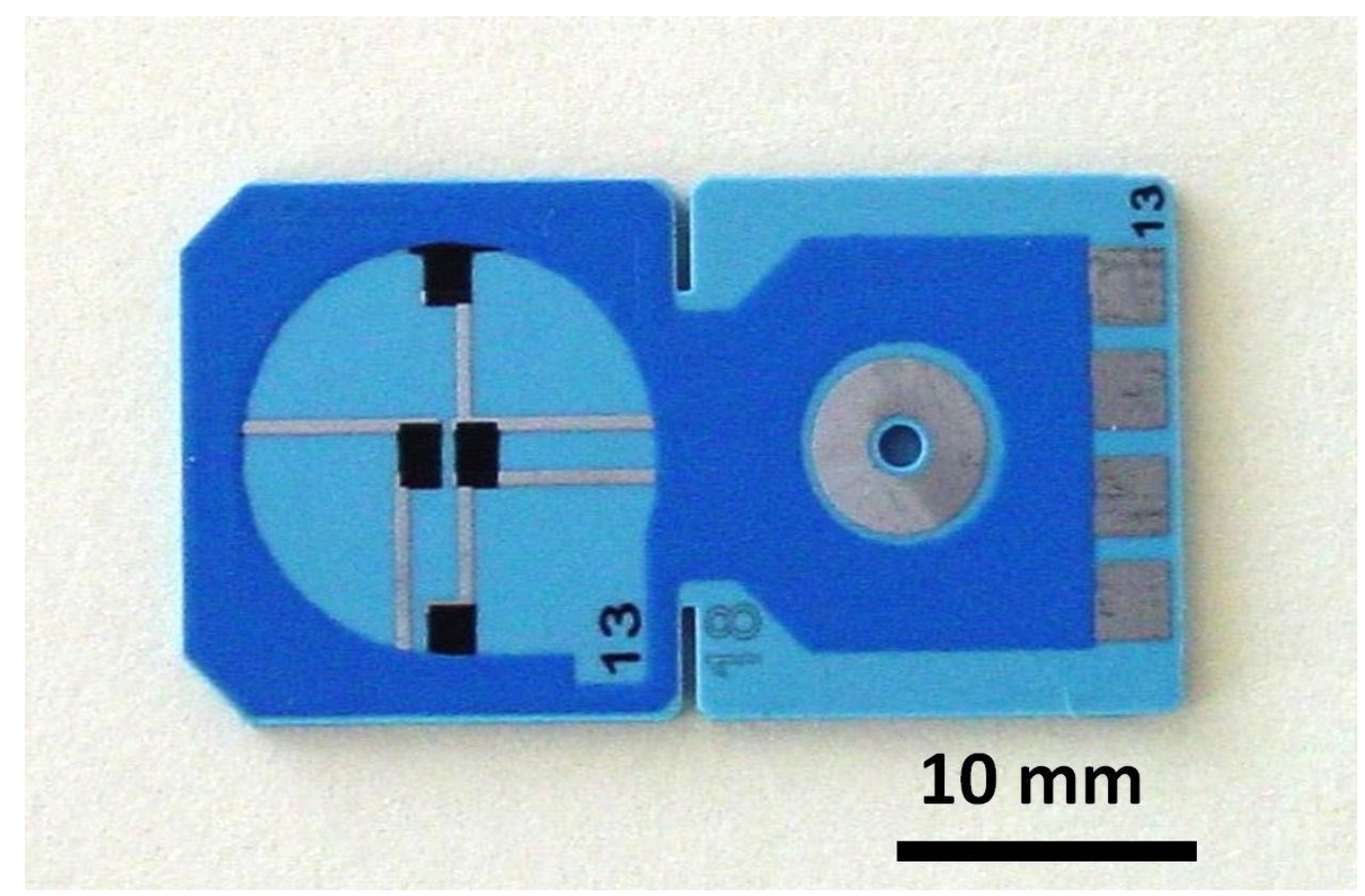

Fig. 13. The 10-kPa pressure sensors tested for long-term stability (made of tape DuPont 951 and thick film resistors DP 2000 series).

Going beyond discrete devices fitted with cables and tubes, one may envision a concept where LTCC sensors are mounted onto a mixed electrical-fluidic substrate, in a way similar to current electronic surfacemount technology (SMT), using common solder bonds for both electrical and fluidic connections and thereby achieving all types of bonding in a single, convenient and fast operation compatible with mass production techniques. Such a device [117] is shown in Fig. 14. The device comprises a bridge conditioning chip on the top surface, yielding a complete ready-to-use pressure sensor. In order for the chip to accommodate for the rather large as-fired offset range of the piezoresistive bridge without losing resolution, coarse offset-trimming resistors had to be integrated in the design. The 3D sensor structure, together with its assembly onto a demonstrator integrated fluidic-electrical PCB, is shown in Fig. 15. A noteworthy design feature is the vertical fluidic access to the membrane in the 5-layer LTCC structure, in order to avoid locally weakening the membrane boundary attachment. The raw bridge sensitivities to pressure for $\sim 100$, 140 and $210 \mu \mathrm{m}$ (fired) thick membranes are ca. 20,8 and $3.2 \mathrm{mV} / \mathrm{V} / \mathrm{MPa}$ respectively (see supplement), matching well with the values calculated using published parameters [104] of the DuPont 951 LTCC and 2041 piezoresistive compositions used in this device. 

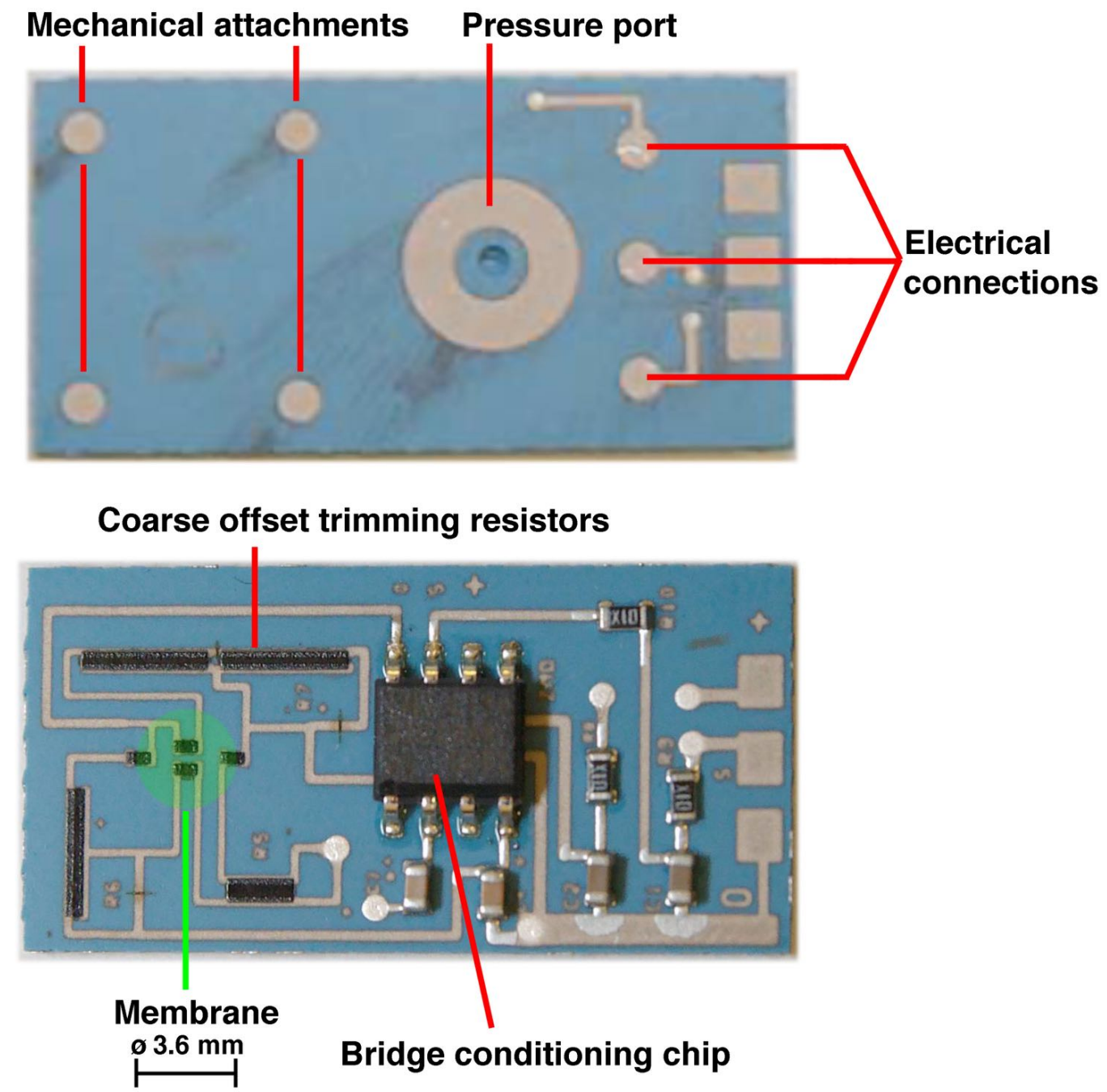

Fig. 14. SMT-mounted pressure sensor [117], comprising an integrated pressure membrane (highlighted in green) together with a signal-conditioning chip.

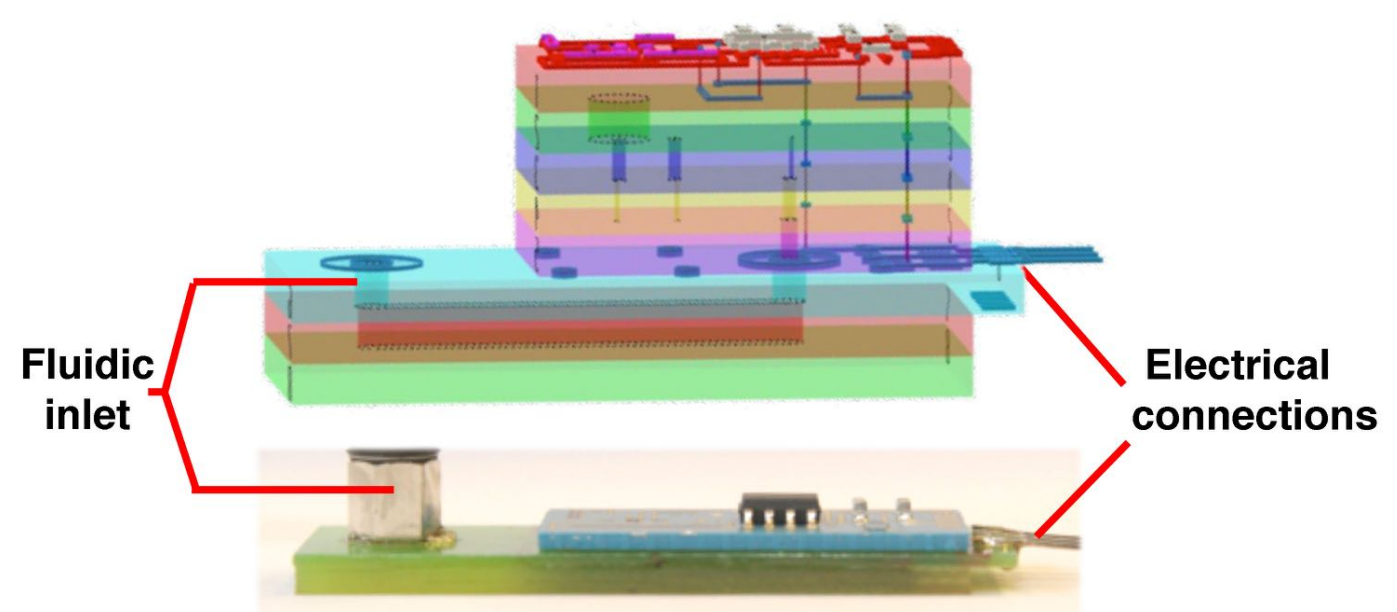

Fig. 15. Pressure sensor [117] on demo PCB: 3D structure (top) and photograph (bottom). 


\subsubsection{Capacitance principle}

The most commonly used basic structure of the capacitive pressure sensor (CPS) includes a circular, edgeclamped diaphragm bonded to a rigid ring and the base substrate. The pressure- induced deflection of the membrane change the distance between the electrodes and, consequently, the capacitance of the sensing structure $[118,119]$. The schematics of the diaphragm-type capacitive ceramic pressure sensor for measurements of the relative gas pressure, based on changing the distance between the electrodes of an aircapacitor is presented in Fig. 16.

Designing the appropriate LTCC structure, with a thin diaphragm and narrow air gap between the co-fired thick-film electrodes, is a challenging task, not only from technological point of view but particularly due to the presence of the stray capacitances and other parasitic elements influencing the sensor's characteristics. In particular by optimizing the design it is possible to achieve higher sensitivity and overall performance. For example, the use of a guard-ring electrode [120] can considerably increase the rms resolution. The sensors for the pressure range $0-10 \mathrm{kPa}$ were manufactured with readout electronics based on a capacitance-to-digital conversion (Fig. 17). The typical sensitivity was $4 \mathrm{fF} / \mathrm{kPa}$ with the rms resolution of $50 \mathrm{~Pa}$, and the temperature coefficient of the sensitivity equal to $0.03 \% /{ }^{\circ} \mathrm{C}$. Digital temperature compensation and calibration [121] yields a maximum $0.4 \% \mathrm{FS}$ error on the compensation range from $10{ }^{\circ} \mathrm{C}$ to $75{ }^{\circ} \mathrm{C}$. Due to the relatively low power of the sensing function of capacitive sensors in comparison to the power needed for other sensing principles, the capacitive LTCC sensor was considered as a candidate for an energy-autonomous sensor application. For the sensors realized with an AD 7746 capacitance-to-digital converter chip, the power consumption, estimated at the supply voltage of $5 \mathrm{~V}$, did not exceed $5 \mathrm{~mW}$ for the high sample rate and $2 \mathrm{~mW}$ for the idle state.
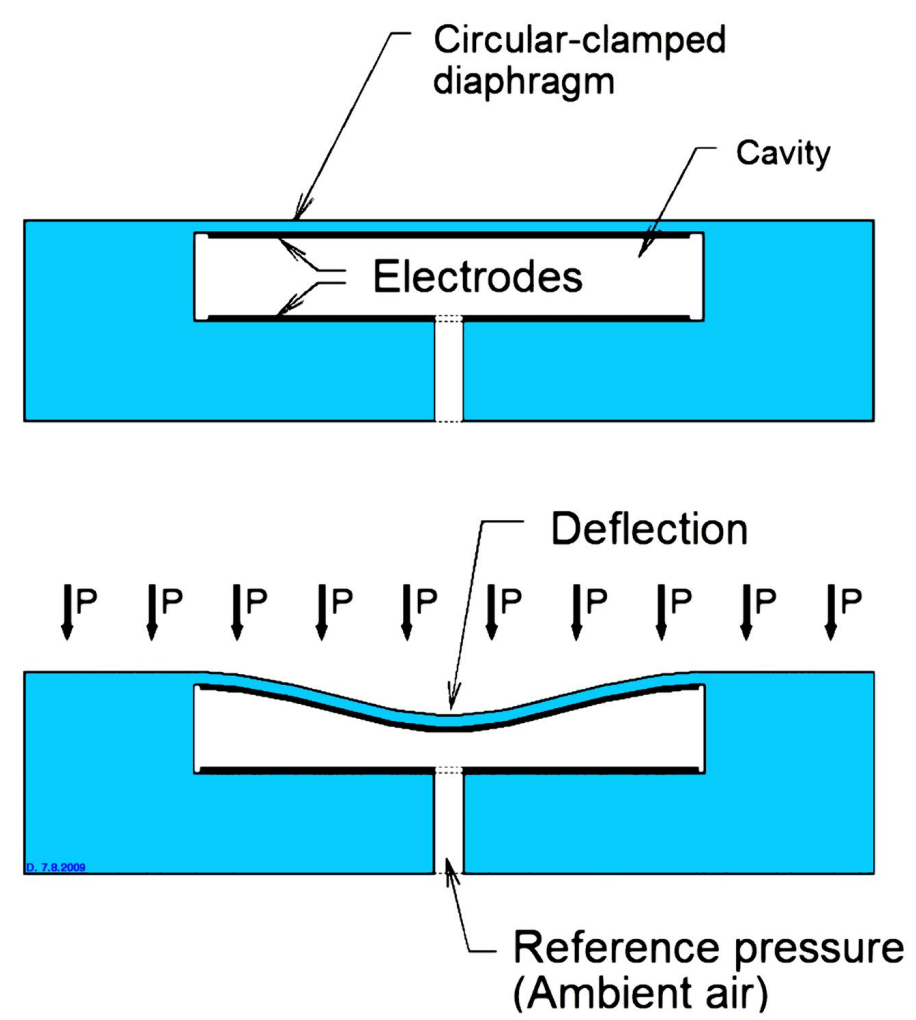

Fig. 16. The principle of the diaphragm-type capacitive pressure sensor 
One drawback of the capacitive diaphragm-type LTCC sensors for measuring air pressure could be the sensitivity to atmospheric humidity and the influence of the different media. Experimental and numerical analyses of the effect of humid atmosphere on the stability of the capacitive CPS $[114,122]$ revealed critical influence of the parasitic capacitances resulting from the thin film of condensed water on the outer walls of the LTCC structure appearing at the relative humidity $>70 \%$. This effect remains a critical problem which should be considered for each specific application separately.

a)

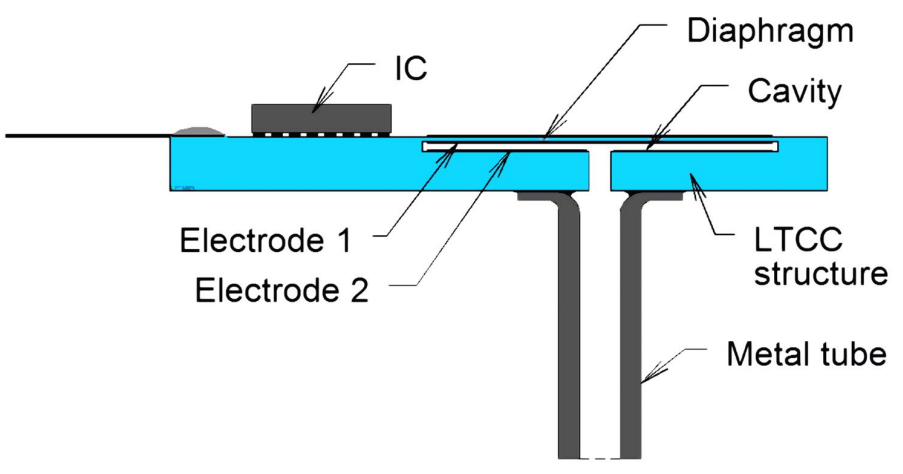

b)

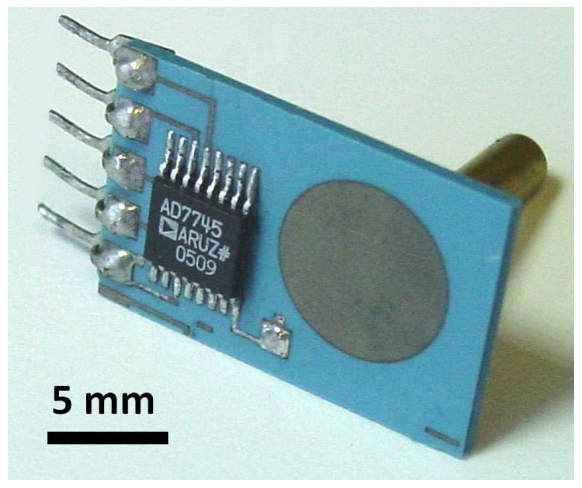

Fig. 17. a) Schematics of the cross-section of the CPS body (not to scale) and b) the prototype with the additional electrode on top and readout electronics realized using AD7746.

\subsection{Accelerometers}

Acceleration can be measured using several different principles: piezoresistive effect, piezoelectric effect or capacitance change. In other words it can be said that acceleration can be assessed exactly like in presented earlier pressure sensors. However, there is one important difference, accelerometers have to consist one extra part - a seismic mass. Therefore, their intricacy is higher in comparison to pressure sensors.

\subsubsection{Uniaxial}

A cross section of the working principle of a uniaxial piezoelectric LTCC accelerometer [123] is presented in Fig. 18a [124]. This particular device consists of a thin LTCC round membrane with a fixed LTCC cylindrical seismic mass in the middle of the membrane. A sensing piezoelectric material is deposited in form of two rings in the regions of the LTCC membrane with the highest stress, as it is presented in Fig. $18 \mathrm{~b}$ [124]. Such concept enables the decrease of the sensor sensitivity to accelerations which are parallel to the sensor surface and increases the device response to accelerations which are perpendicular to the sensor surface. If an acceleration is directed perpendicular to the surface of the sensor, the seismic mass is forced to go down, deforming the membrane. This deformation induces stress, which is the highest in the joining regions of membrane and seismic mass (first region) and LTCC frame (second region). Therefore, if charge is summed from these two regions, the sensor response will be the highest. If an acceleration is directed parallel to the sensor surface, the charge generated onto each region is near zero. Unfortunately, the technology of such devices is significantly more complex in comparison to pressure sensors. A real challenge is the integration of the seismic mass, which is only fixed to the middle of the membrane. Considering a standard LTCC process - lamination of individual layers, it will be relevant that such components cannot be fabricated as other ones, but require other solutions: milling of the chamber around the seismic mass after lamination, lamination of the structure with fugitive spokes which set the proper placement of the seismic mass but which have to been taken off after lamination, or laser engraving of a chamber around the seismic mass. The piezoelectric material as well as the electrodes are deposited using a screen printing process. The measurement setup consists of a mechanical exciter, which generates vibrations of the calibrated device, and charge or voltage measuring circuit. Among the advantages of this sensor working principle is the fact that piezoelectric material does not need power supply and it is generating charge which depends on the amplitude of acceleration. Moreover, the ratio of generated charge to acceleration is more or less constant in a wide range of frequencies. However, such a sensor cannot measure static accelerations. The properties of the fabricated sensor are presented in table 1 . The charge 
sensitivity is a change of charge divided by a value of earth acceleration. The accelerometer working frequency range is limited by $f_{1}$ (lower frequency) and $f_{\mathrm{r}}$ (resonance frequency - upper frequency), whereby the resonance frequency stands for the mechanical resonance of the structure. According to a rule of thumb, the charge sensitivity is no longer constant vs. frequency if the working frequency is higher than 0.5 of $f_{\mathrm{r}}$.

a)

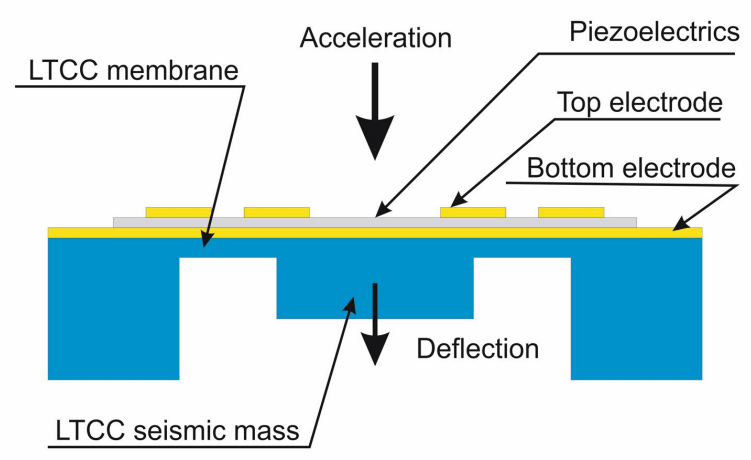

b)

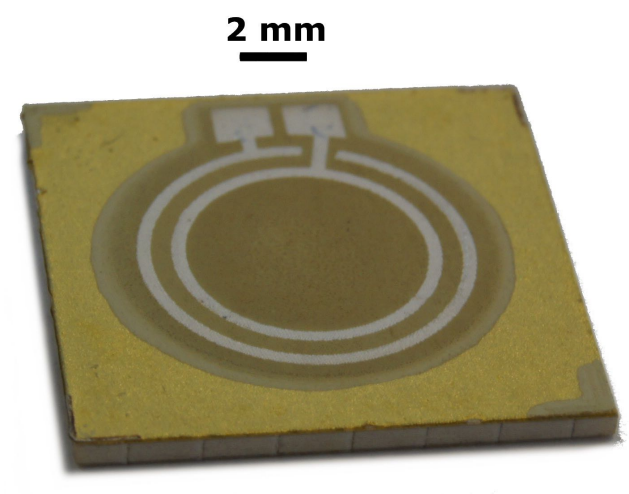

Fig. 18. Piezoelectric accelerometer, a) schematic cross-section visualizing a working principle, b) fabricated sensor

Table 1. The basic parameters of piezoelectric acceleration sensor [124]

\begin{tabular}{|l|c|}
\hline Parameter & Value \\
\hline Charge sensitivity $[\mathrm{pC} / g]$ & 0.28 \\
\hline$f_{\mathrm{r}}[\mathrm{kHz}]$ & $>6$ \\
\hline$f_{1}[\mathrm{~Hz}]$ & 4.4 \\
\hline
\end{tabular}

\subsubsection{Triaxial}

A triaxial LTCC accelerometer utilizing the piezoresistive effect is presented in Fig. 19 [125]. The working principle is very similar to the one shown in Fig. 18a. The first difference is the replacement of bottom, top electrodes and piezoelectrics by piezoresistors. The second one is the replacement of the membrane with a fixed seismic mass which is spanned through four beams, thus setting its proper position. The second change introduces several major effects. The first of them is the reduction of the mechanical resonance frequency of the device, the second one is the increase of the sensor sensitivity and the third one is the enabling of triaxial acceleration measurement. The reduction of working frequency band on one hand is a disadvantage, however, it has to be understand that it is always a compromise between working band and sensor sensitivity in case of accelerometers: the higher the sensitivity, the lower the working band and vice versa. Moreover, taking account the fact that this device was designed as a static accelerometer, the working frequency band does not play an important role. Unfortunately such complex fine construction makes the device less resistant against shocks. On the other hand taking account that typically triaxial accelerometers are less sensitive than uniaxial ones, the necessity of the increase of sensitivity in a current device is obvious. The measurement principle using this sensor is similar to the one presented in the last subchapter. If acceleration is directed perpendicular to the sensor top surface, the seismic mass goes down and deflects all four beams in the same way. These deflection induces stress in beams, which is measured using four piezoresistors. The resistance of each of four resistors is added to each other, this solution increases the sensitivity. Meanwhile, if acceleration is directed parallel to the top sensor surface, the acceleration is measured by two resistors in each of two $\mathrm{x}$ and $\mathrm{y}$ axes. In other words, perpendicular acceleration is measured by four resistors and parallel acceleration is measured by two pairs of resistors. It has to be stressed that by proper placement of each of the resistors in case of perpendicular acceleration resistors which shall measure parallel acceleration give no resistance change and vice versa. The view of the final structure is presented in Fig. 19. The sensitivities for perpendicular acceleration and parallel one are listed in table 2. 


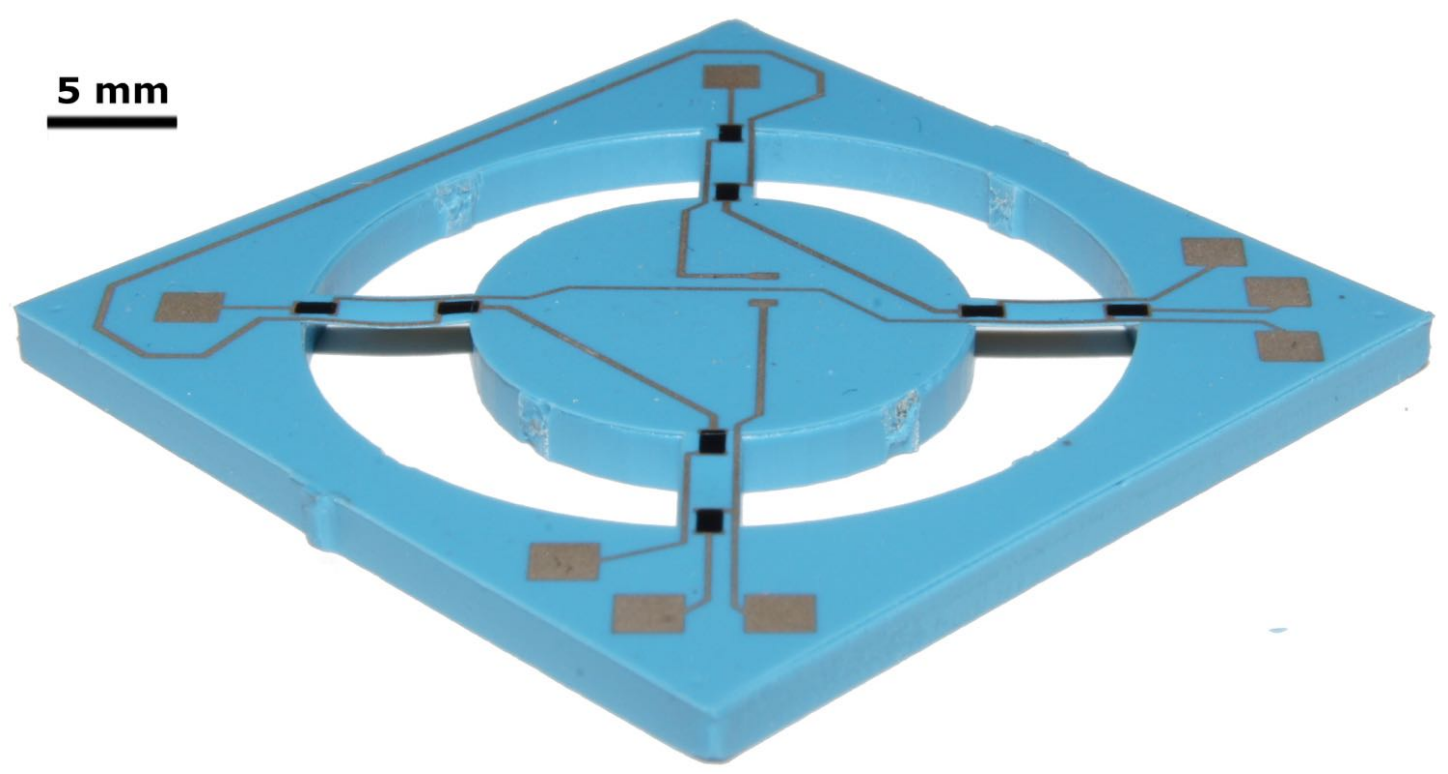

Fig. 19. Manufactured LTCC three axial piezoresistive acceleration sensor

Table 2. The basic parameters of LTCC three axial piezoresistive acceleration sensor [124]

\begin{tabular}{|c|c|}
\hline Parameter & Value \\
\hline Perpendicular sensitivity $[\Omega / g]$ & 24.3 \\
\hline Transversal sensitivity $[\Omega / g]$ & 2.8 \\
\hline
\end{tabular}

\subsubsection{Piezoelectric accelerometer in SMD package}

The model of a piezoelectric accelerometer in SMD package [126] which consists of a cantilever made of LTCC and PZT tapes is presented in Fig. 20. At the free end of the beam the additional seismic mass is placed. The cantilever is fixed to a frame, which acts as a part of the package.

The manufacturing process of the device contains several steps. First, the middle electrodes are screen printed on both sides of HL2000 (Heraeus) tape. Next, the PZT tapes (Pz27 based tape, Meggitt, Denmark; thickness of $t_{\mathrm{PZT}}=50 \mu \mathrm{m}$ in green state are laminated on both sides on the LTCC and then top/bottom gold electrodes are applied. The seismic mass is formed in 18-layer LTCC (Fig. 21a). The cantilevers (Fig. 21b) are cut using a laser (ProtoLaser U, LPKF, Germany). The elements are chemically laminated using a proper solvent (Fig. 21c). The structures are sintered at $950^{\circ} \mathrm{C}$. Finally the top and bottom caps are joined using a sealing glass (SG-683K, Heraeus). The PZT layers are poled at elevated temperature using a large electric field in a serial bimorph configuration. The device prepared as a SMD (surface mounting device) is presented in Fig. 22. The sensor exhibits good linearity with a sensitivity of $0.76 \mathrm{pC} / \mathrm{g}$ (Fig. 23a) and a flat response up to $500 \mathrm{~Hz}$ with resonance at $1.9 \mathrm{kHz}$ (Fig. 23b). The safety acceleration for the device is about

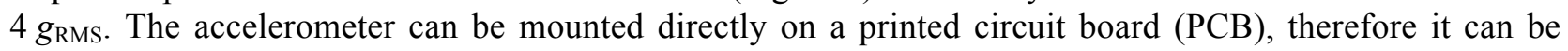
applied for vibration monitoring in various systems. 


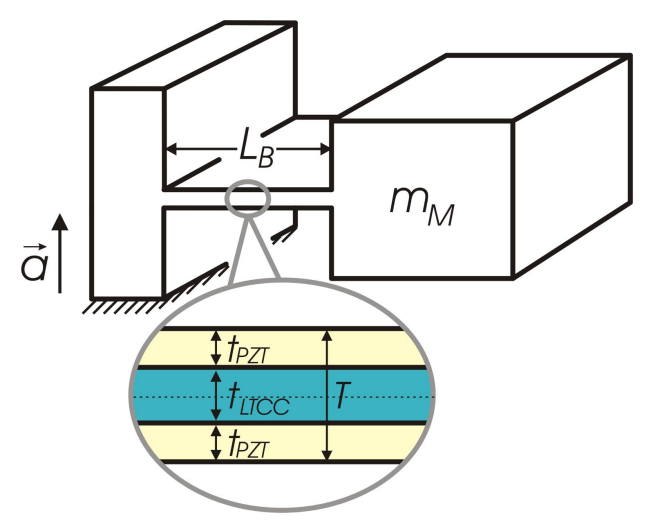

Fig. 20. Design of the uniaxial accelerometer with main dimensions (not to scale)
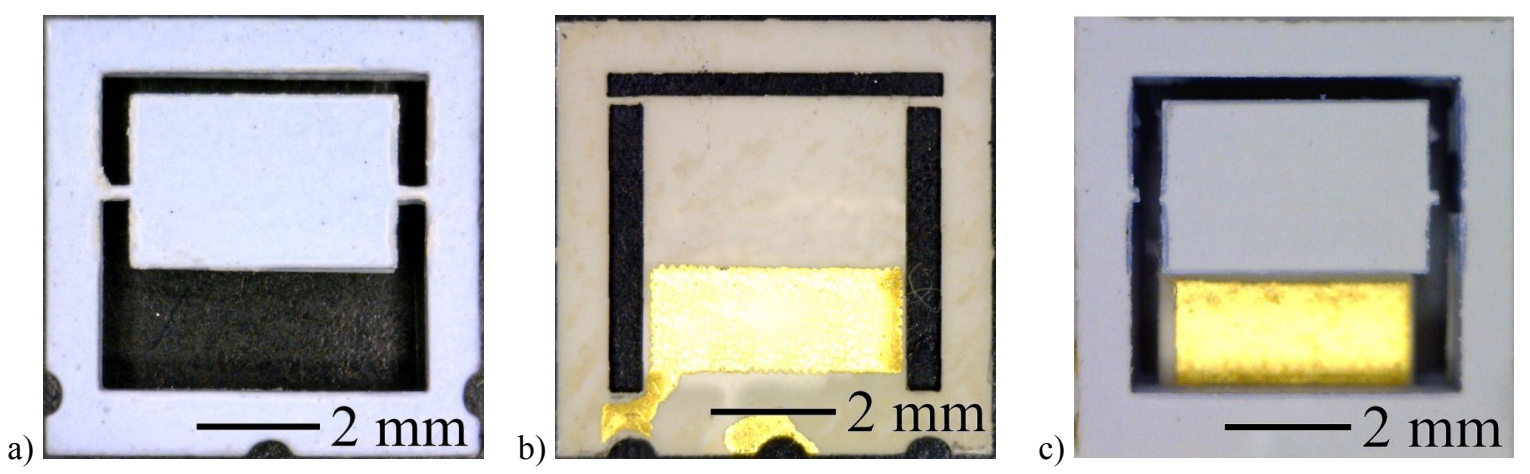

Fig. 21. a) LTCC with formed seismic mass, b) PZT/LTCC cantilever with electrodes and c) joined elements

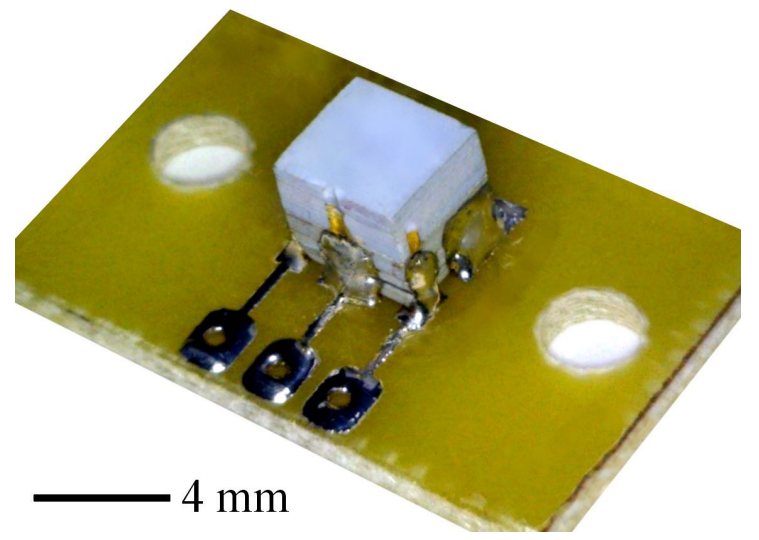

Fig. 22. Accelerometer soldered to a holder

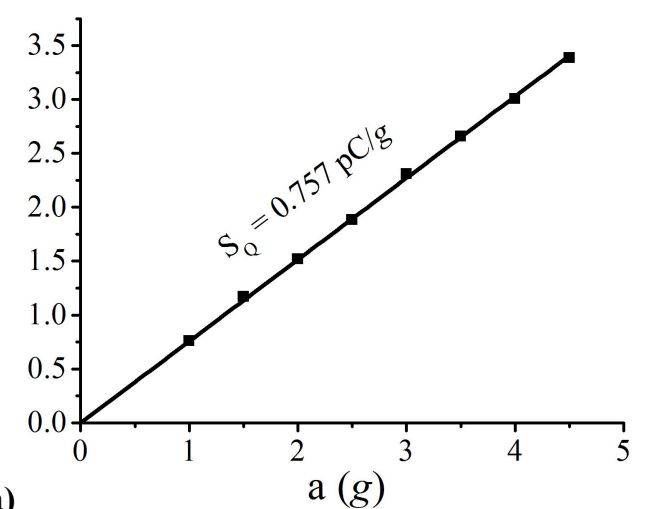

a)

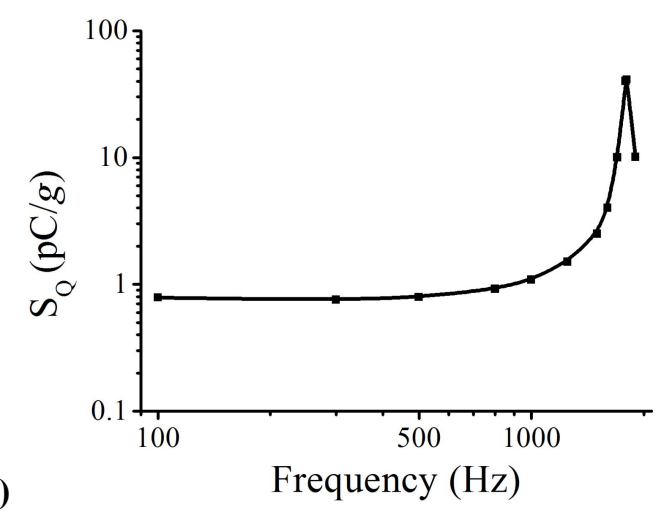

Fig. 23. Results of measurements: a) sensitivity at $100 \mathrm{~Hz}$, b) spectrum at $1 \mathrm{~g}$ 


\subsection{Fluid flow sensors}

\subsubsection{Turbine}

The possibility of the manufacturing of complex 3D mechanical structures using LTCC also enables the fabrication of turbine-based fluid flow sensors [127]. The sensor consists of a fluid inlet, outlet and roller with a turbine. All these components are fabricated using LTCC technology. The final turbine and the sensor with turbine are presented in Fig. 24. The measuring setup, which is shown in Fig. 25a, consists of light emitting and light detecting circuits and a frequency measuring unit (in this version an oscilloscope). The turbine is placed perpendicular to the lighting route between lighting emitting-detecting circuits. The fluid flow induces rotation of the turbine which cause interruption of the lighting route by a turbine. These interruptions are detected as voltage changes by light detecting circuit and then counted by oscilloscope. Hence, based on the lighting pulse count number the fluid flow can be calculated. The lighting route can be as well integrated directly with the sensor as it was shown in [128]. This solution permits conducting the measurements using a much simpler measurement setup (without oscilloscope). The advantage of this type of sensor is much lower sensitivity of measurements for fluid temperature changes. Unfortunately, mechanical sensors are much more technologically sophisticated in comparison with thermal based flow sensors. The calibrating curve, which indicates the sensor response vs. flow velocity, is presented in Fig. 25 b. The sensitivity is around 25 [turns $/ \mathrm{mL}]$.

a)

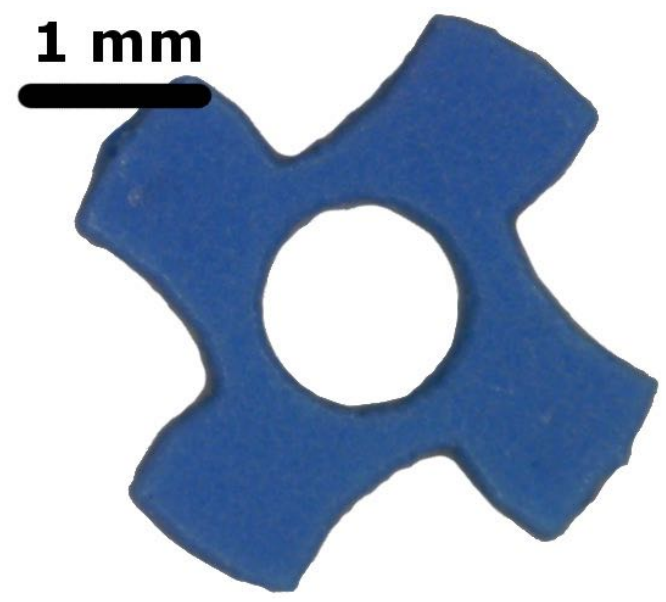

b)

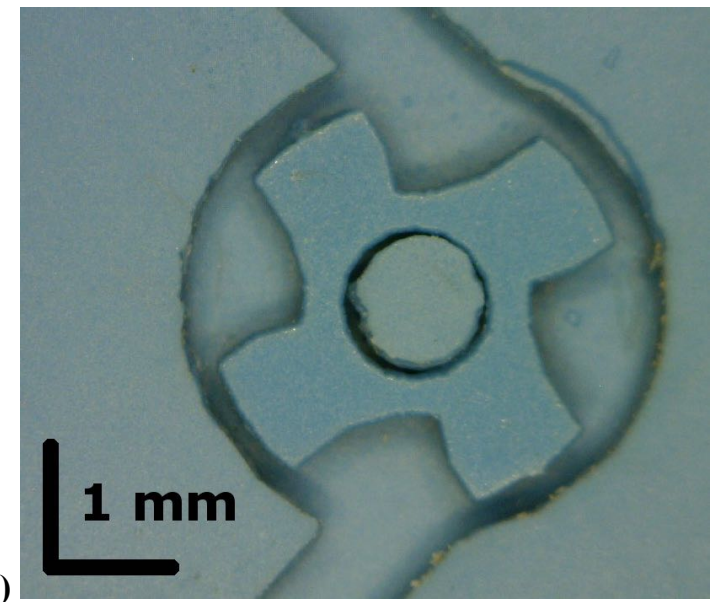

Fig. 24. LTCC fluid flow sensor, a) single turbine, b) sensor

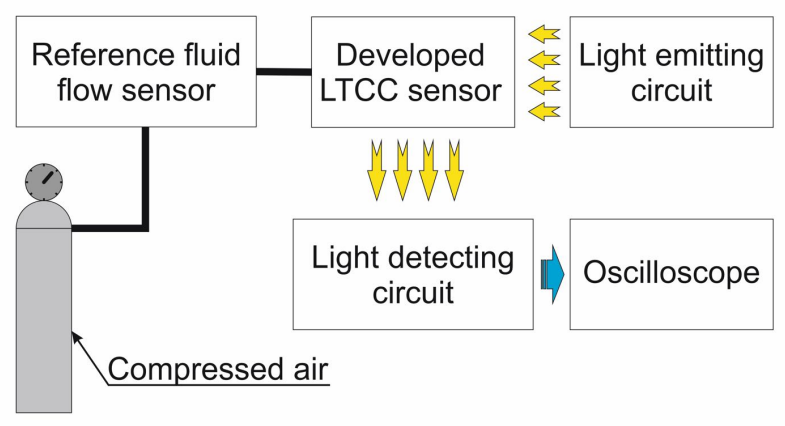

b)

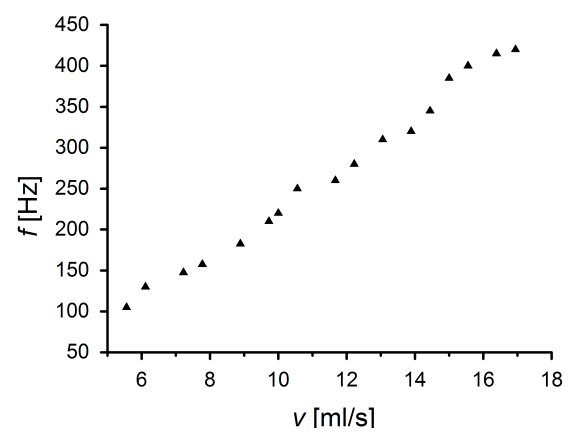

Fig. 25. Calibration of LTCC turbine based flow sensor, a) measurement setup and working principle, b) calibrating curve 


\subsubsection{Thermo-resistive}

The dependence of heated component thermal losses on fluid flow velocity can be utilized in the fabrication of LTCC fluid flow sensors [129]. For these devices, the dependence of the flowmeter response from the fluid as whole and atmospheric ambient temperature is very important. The simplest thermo-flowmeter consists of only one heating component (e.g. resistor) and one temperature sensing component (thermistor, e.g. Pt100). The resistor is electrically heated up to a fixed temperature or at constant power. Temperature can be measured by the heater itself (if the heater is a thermistor) or by an adjacent thermistor / thermistor pair. It is obvious that fluid flow will cool the resistor, hence, its temperature will be dependent on the flow velocity. Based on such principle, it is possible to calibrate the sensor. However, variations in the fluid temperature will induce errors in the flowmeter response. Hence, an upgraded version of such sensor is typically used, as presented in Fig. 26a. Such sensor besides, the aforementioned resistor/ temperature sensor has one more reference sensor used for fluid temperature measurement. In the example presented in Fig. 26a, this second thermometer is placed onto Bridge 1, and the resistor with first thermometer are placed onto Bridge 2. For such a combination, any influence of fluid temperature variation can be easily compensated by external electronics. The measurement setup which was used for calibration of this sensor is shown in Fig. 26b. The flow is forced using compressed air and it is fixed by a pneumatic valve which is coupled with a reference flowmeter. The resistor is electrically heated by an external power supply and the resistance of both thermistors (thermometers) is measured using multimeters. The technology of such devices is not very complex and can be carried out using standard LTCC processes. An exemplary fabricated device is presented in Fig. 27 and its basic sensor parameters are given in table 3. A similar device was developed for the application in biological fluid systems using embossing process and it's technology and properties are presented in [130].

a)

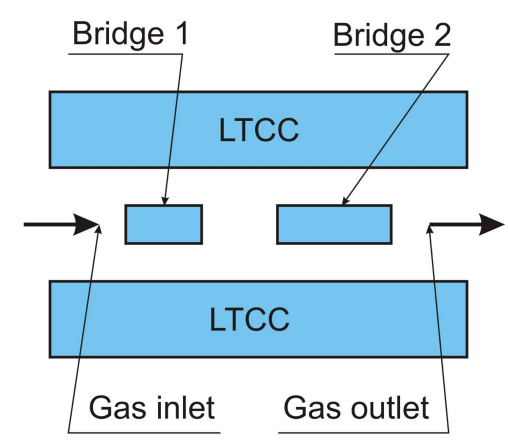

b)

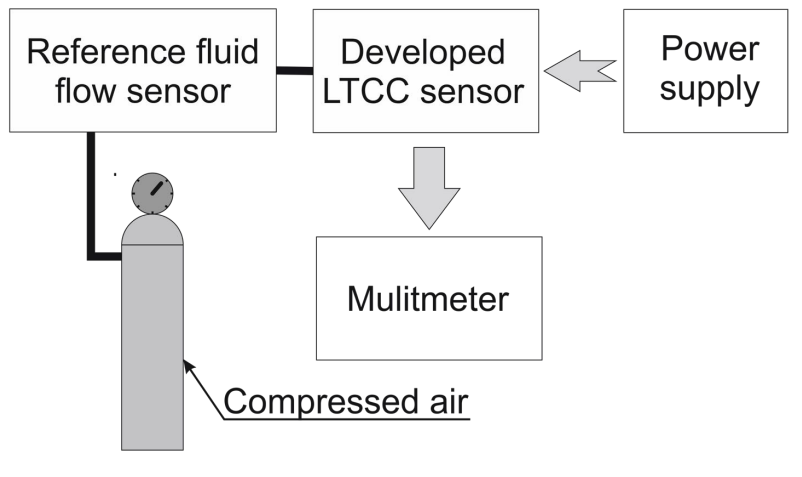

Fig. 26. Three element gas flow sensor, a) schematic diagram of working principle [124], b) measurement setup

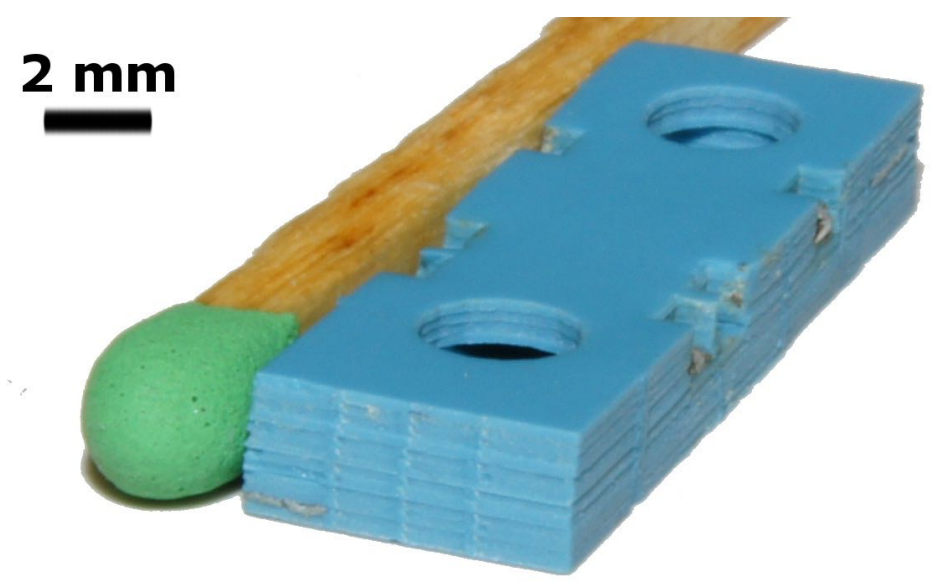

Fig. 27. Fabricated three element gas flow sensor 
Table 3. The parameters of the flow sensor [124]

\begin{tabular}{|l|c|}
\hline Sensor parameter & Value \\
\hline Output response [\%/mL] & 2.73 \\
\hline Measuring range [mL/s] & $2.5-36$ \\
\hline Max. relative error [\%] & 6 \\
\hline Error of sensor [\%] & 8.2 \\
\hline Input working pressure [MPa] & $0.01-2$ \\
\hline
\end{tabular}

A thermoresistive flow sensor that is more technologically advanced is shown in principle in Fig. 28, with the structure and core of the device shown in Fig. 29 [117]. This device comprises thermistor "wires", realized in the form of thin LTCC bridges carrying PTC thermistors, suspended within a channel of rectangular cross-section. A versatile layout was chosen, in order to allow measurement of flow using both, the calorimetric and anemometric principles:

- Calorimetric (for low flows and directional): measurement of the thermal imbalance between the resistors $\mathrm{R} 2$ and $\mathrm{R} 3$ that are adjacent to the heater resistor Rheater

- Anemometric (for higher flows and not directional): measurement of the increase of heat loss of the heater resistor Rheater (usually kept at constant temperature difference above the reference RT) with increasing flow

The result of both calorimetric and anemometric measurement are shown in Fig. 30. The calorimetric measurement range could not be investigated in detail, as saturation was observed even at the lowest adjustable flow, indicating an absolute sensitivity in the linear part greater than $4 \mathrm{mV} /(\mathrm{L} / \mathrm{min})$, with mass flow expressed for air in normal conditions. On the other hand, the investigated flow range was suitable for measuring flow with the anemometric signal. Such a combined measurement allows, using appropriate signal processing, both measurement of low flows with high sensitivity, using the calorimetric principle, and that of high flows, using the anemometric principle and keeping the sign of the calorimetric signal as an indicator of flow direction. The sensitivity of the anemometric power signal to flow decreases smoothly with increasing flow, with average values of $8.8,4.7$ and $3.3 \mathrm{~W} /(\mathrm{L} / \mathrm{min})$ for the $0 \ldots 20,20 \ldots 40$ and $40 \ldots 80 \mathrm{~L} / \mathrm{min}$ flow ranges respectively. 


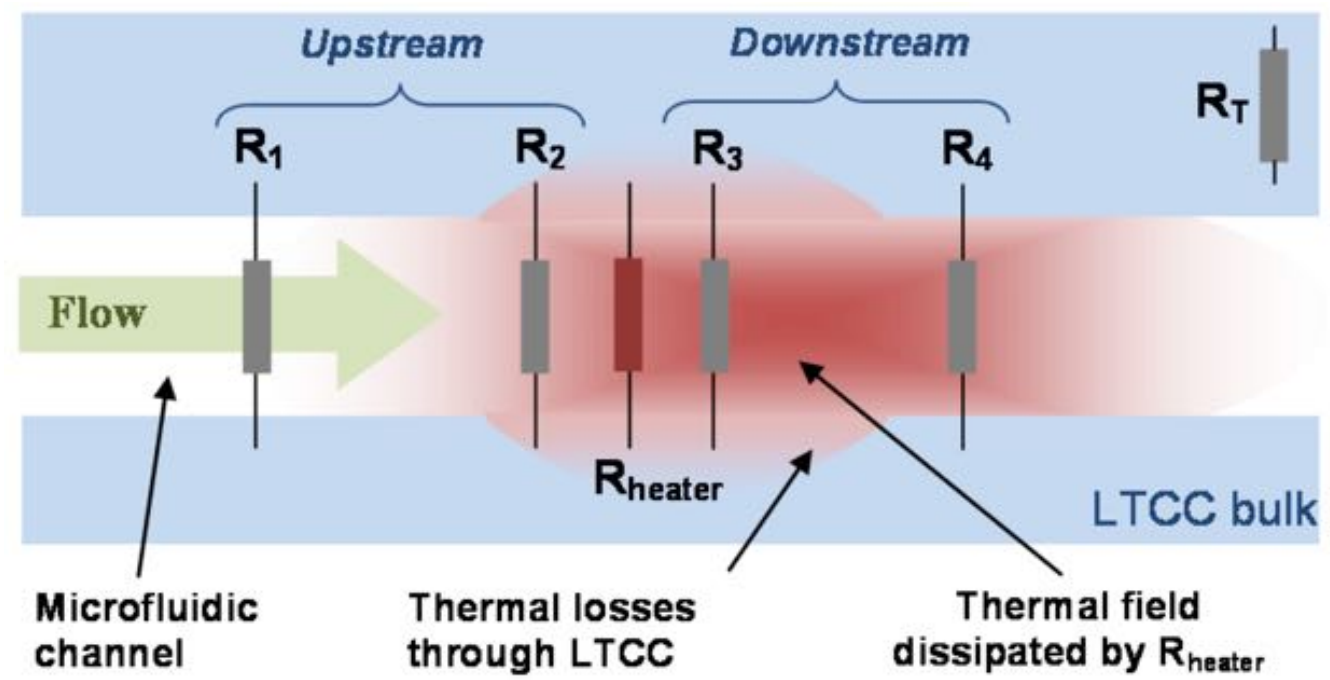

Fig. 28. Principle of a versatile thermal flow sensor [117], with resistors for both calorimetric and anemometric sensing principles.

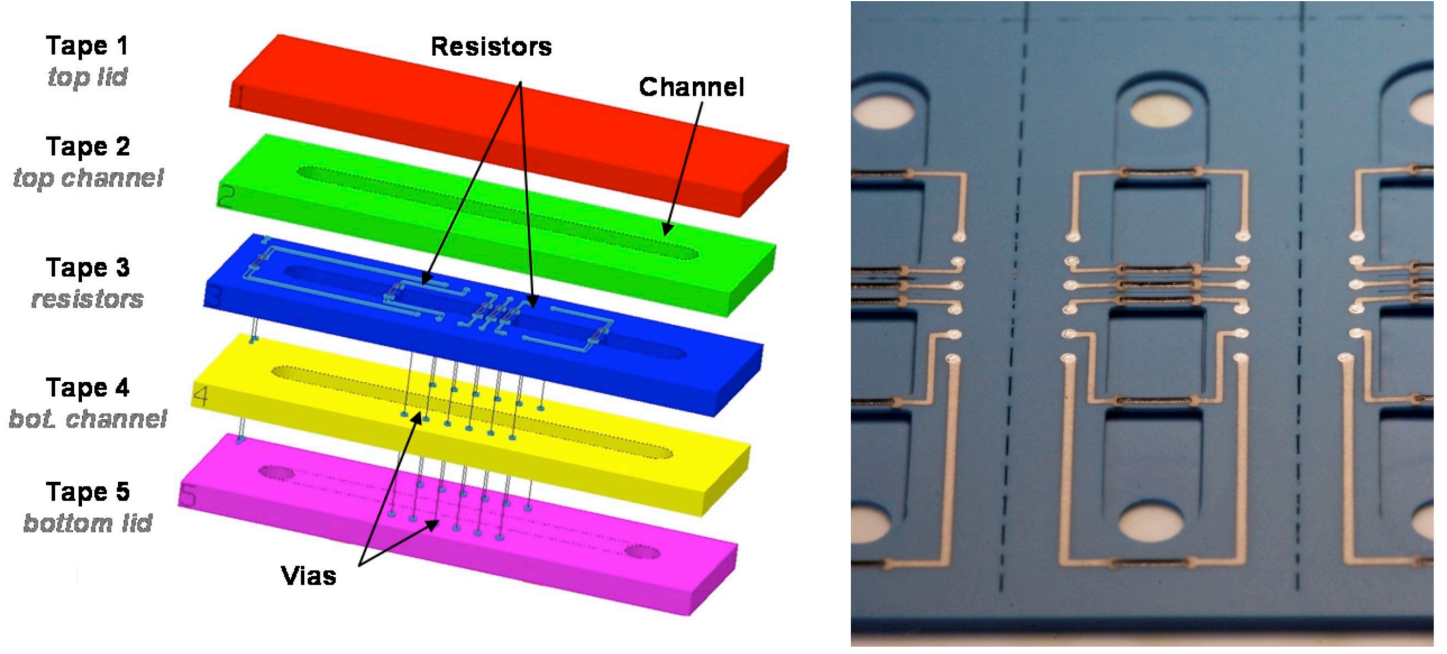

Fig. 29. Flow sensor [117] 3D structure (left) and photograph of the bottom three layers (right), showing the inner sensing layer with the resistive bridges.

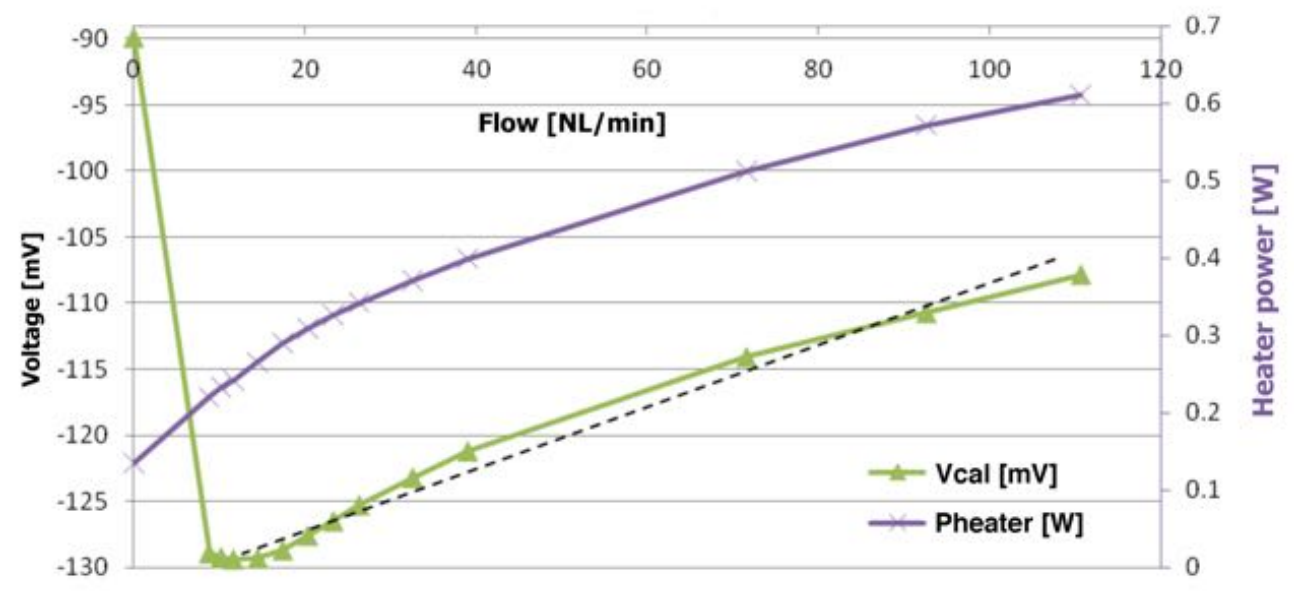

Fig. 30. Calorimetric (Vcal) and anemometric (Pheater) flow sensor output, as a function of flow [117]. 


\subsection{Eddy current sensors}

The detection of distance or position control of metal objects can be conducted using eddy current sensors. These sensors consist of a simple multilayer coil, whose inductance depends on coil to the metal object distance. Hence, LTCC technology is well suited for the fabrication of such devices. The inductance change of the inductor is typically measured using an oscillating circuit, which can be integrated directly with the coil into one ceramic substrate thanks to the LTCC technique $[15,131]$. The measuring principle using eddy current sensors is presented in Fig. 31a. The inductance change and depth of field penetration of eddy current sensors depend on many factors. The most important coil dimensions are: distance between conductive paths of coil $(S)$, conductive path width $(L)$, thickness of LTCC tapes - distance between coil layers $(t)$, numbers of turns and number of coil layers. These parameters are shown in Fig. 31b. Moreover, the coil inductance depends both on the properties of the used LTCC tapes and existence of ferrite core. The factors which affect the measurements as well are the conductivity and permittivity of the target material and the excitation frequency. Therefore it is necessary to adapt the coil design to the particular application. A crucial parameter for the measurement quality of an eddy current sensor is the quality factor $Q(x)$ of the sensor coil. It is a function of the distance $x$ and defined by the equation 1 (where: $L_{0}$ and $R_{0}$ are the unloaded values for the inductance and resistance of the sensor coil and $\Delta L(x)$ and $\Delta R(x)$ are the respective distance dependent portions) [131].

$$
Q(x)=\omega \cdot\left[L_{0}+\Delta L(x)\right] /\left[R_{0}+\Delta R(x)\right]
$$

The sensitivity $\Delta \mathrm{Q} / \Delta \mathrm{x}$ at each position $\mathrm{d}$ is estimated as a ratio of the difference between the quality factor Qd at this position and the quality factor at the previous position $\mathrm{Q}(\mathrm{d}-1)$ and the difference of the associated distances $x d$ and $x(d-1)$.

$$
\Delta Q /\left.\Delta x\right|_{d}=\left[Q_{\mathrm{d}^{-}} Q_{\mathrm{d}-1}\right] /\left[x_{\mathrm{d}}-x_{\mathrm{d}-1}\right]
$$

From equation (2), it is evident that the change of the quality factor has a crucial influence on the sensitivity.
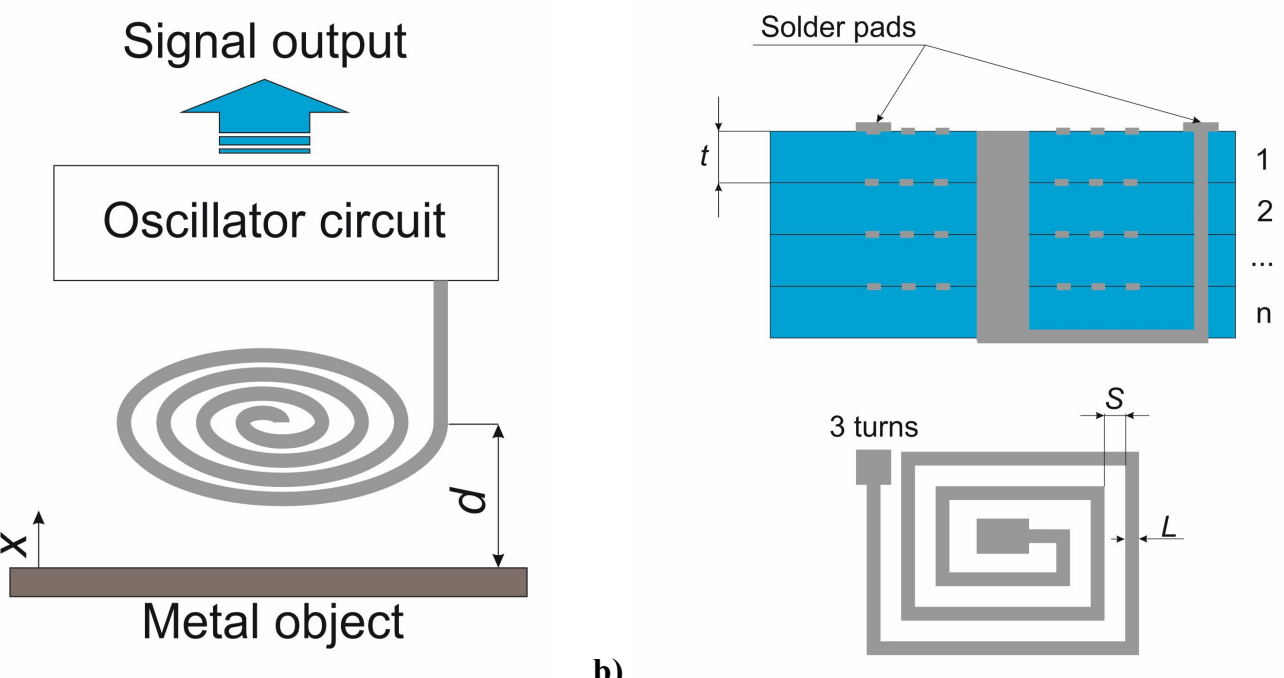

b)

Fig. 31. Eddy current sensor, a) measuring principle, b) basic dimensions of the sensor

Table 4. Overview of basic parameters for LTCC eddy current sensor coils (geometric parameter see Fig. 31b)

\begin{tabular}{|c|c|c|c|c|c|c|c|c|c|}
\hline $\begin{array}{c}\text { Footprint } \\
{[\mathrm{mm} \times \mathrm{mm}]}\end{array}$ & $\begin{array}{c}\boldsymbol{L} / \boldsymbol{S} \\
{[\mu \mathrm{m} / \mu \mathrm{m}]}\end{array}$ & Turns & $\begin{array}{c}\boldsymbol{T} \\
{[\mu \mathrm{m}]}\end{array}$ & $\begin{array}{c}\text { Layer } \\
\text { No }\end{array}$ & $\begin{array}{c}\boldsymbol{L}_{\mathbf{0}} \\
{[\mu \mathrm{H}]}\end{array}$ & $\begin{array}{c}\boldsymbol{R}_{\mathbf{0}} \\
{[\Omega]}\end{array}$ & $\boldsymbol{Q}$ & $\begin{array}{c}\text { Range } \\
{[\mathrm{mm}]}\end{array}$ & Ref. \\
\hline $10 \times 10$ & $80 / 80$ & 20 & 150 & 5 & 50 & 120 & $2.6 \%$ & 3 & {$[131]$} \\
\hline $15.7 \times 8.7$ & $130 / 130$ & 16 & 100 & 5 & 260 & 80 & $20 \%$ & 4 & {$[132]$} \\
\hline $4.7 \times 2.4$ & $80 / 60$ & 7.5 & 220 & 4 & 2 & 13.5 & $0.9 \%$ & 1 & {$[15]$} \\
\hline $\begin{array}{c}4.7 \times 2.4 \\
\text { (embossed) }\end{array}$ & $80 / 60$ & 7.5 & 220 & 4 & 2 & 5.7 & $2.2 \%$ & 1 & {$[15]$} \\
\hline
\end{tabular}


Eddy current sensors feature excellent robustness in harsh environments due to the fact that they are inherently immune to non-metallic pollutions. LTCC multilayer technology is favoured to fabricate eddy current coils, which can work at high temperatures, because the ceramic is stable up to $600^{\circ} \mathrm{C}$, moreover it withstands a wide range of chemicals. Different coils are already presented in the literature. Table 4 gives a summary of some LTCC coils and their basic parameters.

The footprint of the sensor influences the sensing range: larger coils inspect a greater volume of material from any given position, since the magnetic field flows deeper into the measured object, while smaller coils are more sensitive to defects. A 3D planar non-contact proximity sensors fabricated using LTCC technology is presented in [132]. The sensor has a footprint of $10 \times 10 \mathrm{~mm}$ and is built up using the DuPont 951 material system. The measurement coil exhibits a high resistance of $120 \Omega$, resulting in a low quality factor. A further LTCC coil is used as wheel balancing sensor for blade tips of gas turbines or aero-engines at temperatures up to $600^{\circ} \mathrm{C}$ [133]. The LTCC coil is also made from DuPont 951 tape with an unfired

thickness of $114 \mu \mathrm{m}$ and has a footprint of $15.7 \times 8.7 \mathrm{~mm}$. In spite of the fact that the conductor path resistance is high, the coils quality factor reaches $20 \%$ due to the high coil inductance of $260 \mu \mathrm{H}$. This high value is a consequence of the use of thin LTCC tape with a thickness of $100 \mu \mathrm{m}$ and the associated high mutual inductance.

The smallest coil in this comparison is framed to match the 6332 SMD package type and has a coil area of $4.7 \mathrm{~mm} \times 2.4 \mathrm{~mm}$ [15]. It is suitable for the thickness control of nonconductive foils and can be assembled in arrays. The inductance of the coil is small due to the small dimensions and a low mutual inductance. Therefore, the quality factor for coils fabricated with LTCC standard technologies is low. One method to achieve higher quality factors for a given coil geometry is the reduction of the resistance. This can be attained with embossed conductor paths [134]. The method enlarges the conductor cross section. Fig. 32a and $32 \mathrm{~b}$ compares the cross sections of a screen printed conductor path and an embossed one. The thickness of screen printed conductors amounts to $7 \mu \mathrm{m}$. The embossed conductor path features a nearly rectangular cross section with a thickness of $35 \mu \mathrm{m}$ after firing. The width of $70 \mu \mathrm{m}$ results in this case from the filling method. With this technique the quality factor can be increased by a factor of two. The associated increase of the sensitivity according to equation 2 is depicted in Fig. 32c. From the appliance of this knowledge follows consequently, that the refinement of layer thickness and the use of innovative fabrication methods such as embossing has the potential to realize low-loss coils with high quality factor in LTCC multilayer technology.
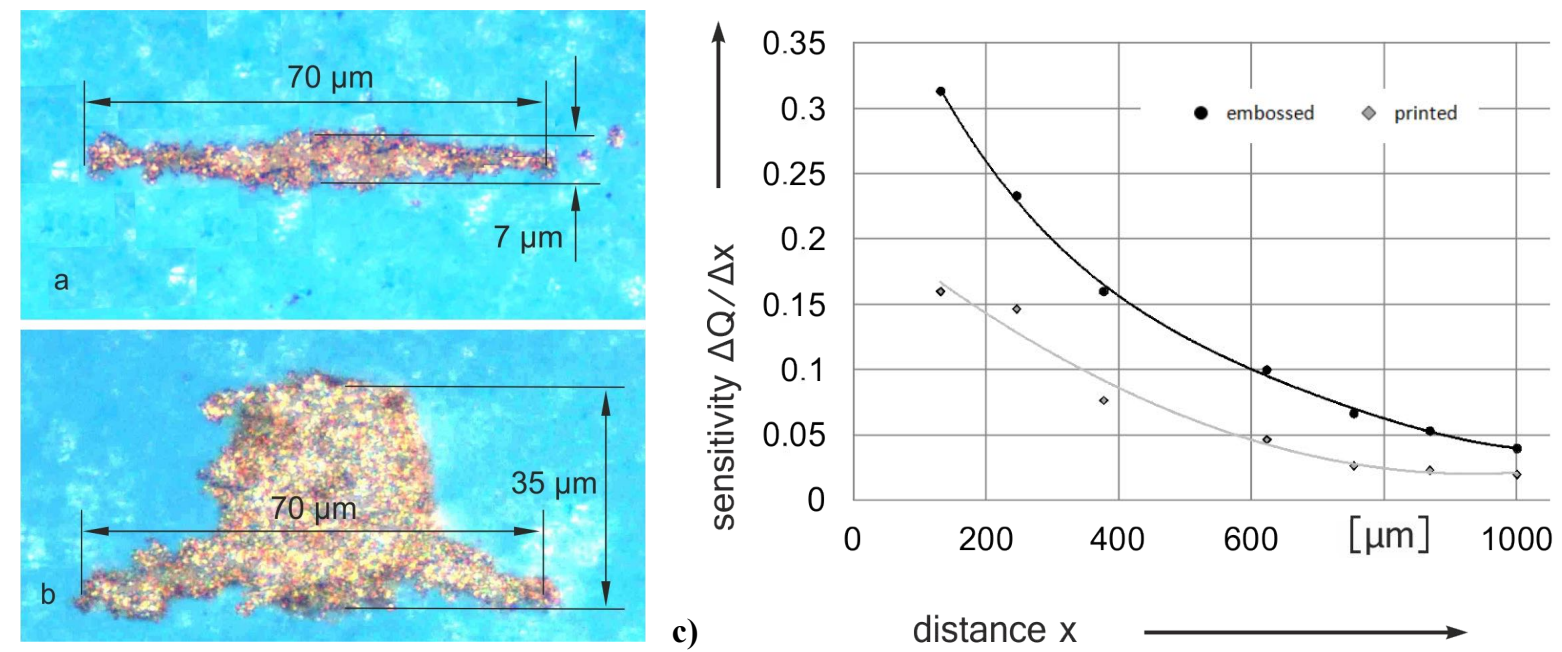

Fig. 32. Coils comparison, a) cross section of a screen printed conductor path, b) cross section of an embossed conductor path, c) comparison of the sensitivity for a sensor with printed coil and embossed coil [15]. 


\subsection{Force sensor}

\subsubsection{LTCC cantilever force sensor}

Thick-film technology allows the fabrication of simple, low-cost piezoresistive force sensors, which have found use in medical instrumentation, such as rehabilitation robotics [135, 136]. Depending on the force range, different geometries such as cantilever beam, four-point bridge beam and double-ring membrane are found to be adequate, among those the cantilever is suitable for the lowest forces [137, 138]. However, the measurement of forces below ca. $100 \mathrm{mN}$ is unpractical with simple thick-film alumina beams furnished with thick-film piezoresistive bridges, as the cantilever would have to be very small, very long and/or very thin. Therefore, replacing the alumina cantilever with an LTCC one, keeping the same alumina base (Fig. 33), presents three important advantages in fabricating low-range sensors, resulting in the LTCC device exhibiting a force sensitivity ca. $5 \times$ of the standard alumina one, in spite of having only one active resistor pair [139]:

1) Elastic modulus. LTCC material has a lower elastic modulus than alumina, $\sim 110$ vs. $\sim 340 \mathrm{GPa}$ [66]. Although compensated in terms of intrinsically achievable signal by lower strength, especially long-term [140], this feature does allow the improvement of the sensitivity by a factor of $\sim 3$, all other parameters are kept constant.

2) Laser cutting. LTCC tapes can be easily structured in the green state, e.g. by laser cutting, to create narrow bridges at the sensing zones [68]. Besides the resulting sensitivity improvement, this technique allows keeping the maximum stress away from the attachment, improving signal quality [137]. Similar structuration of alumina beams in the fired state is not favourable, as it creates defects and results in decreased strength [141]

3) Multilayer. Provided that the force sensor is unidirectional, as in the case of the presented device, a further improvement in sensitivity of the resistor pair in compression can be achieved by stacking two layers with different cut-outs, in order to concentrate compressive stresses for the cross section (Fig. 34).

The resulting device has been further modified and fitted with a polymer membrane to convert it into an ultra-low pressure sensor for a neonatal resuscitator [142]. Notwithstanding the very promising results, there are still issues that need to be addressed. Some of the thinnest devices, for measuring low forces, encountered apparent signal drift, the cause of which, be it defects in resistors, local delamination between tapes and/or plastic deformation in conductors, is at this time not known unambiguously [142].

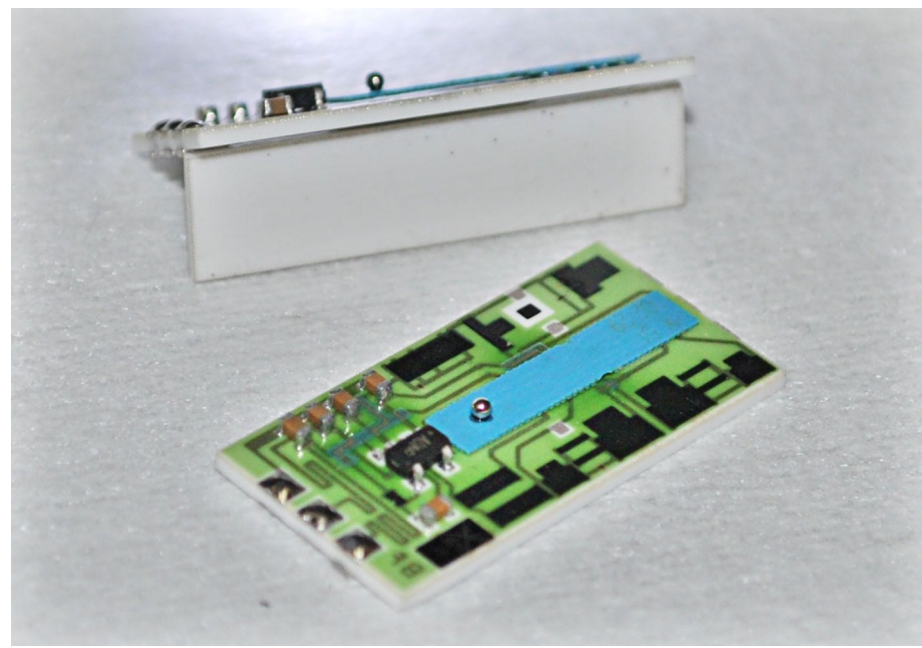

Fig. 33. Two force sensors with alumina base and LTCC cantilever (blue), with the top device being oriented so that the gap between cantilever and base is visible. 

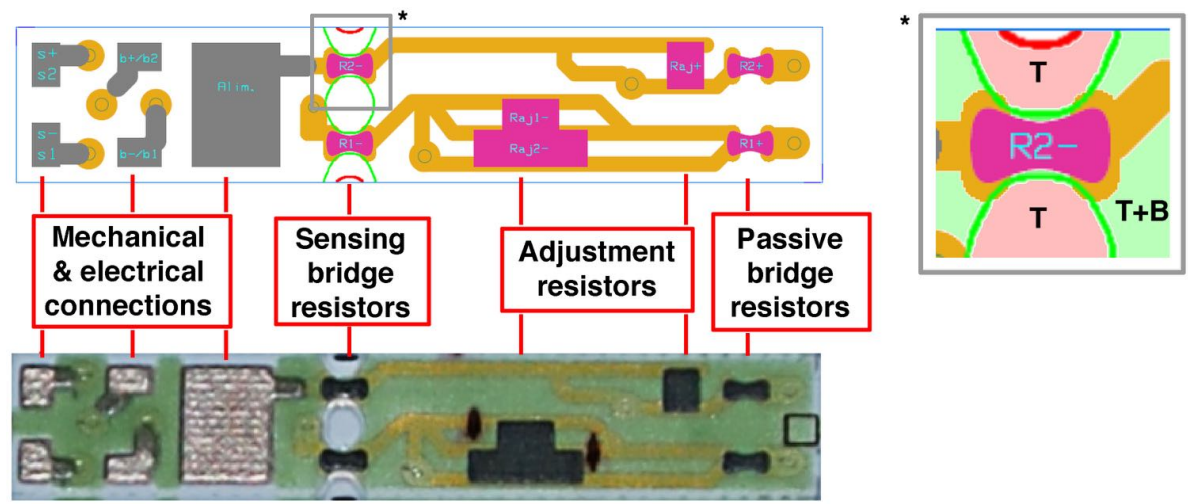

Fig. 34. Layout (top) and image (bottom) of the bottom face of the LTCC cantilever (wires running within the device and essentially blank top face not shown). Inset: detail of the differential cut-out of both LTCC layers, showing a larger area for the top (T) than for the bottom (B) tape.

\subsubsection{Force sensor utilizing ultrasonic waves}

Ultrasonic waves propagated in substrates in general are sensitive to deformation of the material, hence they can be utilized to detect forces or deflections. The LTCC force sensor utilizing ultrasonic waves [143] consists of a ceramic cantilever beam, with two IDTs on its surface. A force applied to the free end of the cantilever, as presented in Fig.35, results in a deformation of the structure. The changes of the IDTs and the waveguide dimensions during deformation, result in a frequency shift, when a pair of transducers works in oscillator mode. Maximum strain occurs in a transducer near a fixture, hence the transducer should be used as an exciting element and the other as a receiver and act as a feedback for the amplifier.

The device is manufactured in several steps. Fist, the LTCC plate as a substrate for the PZT layer and the LTCC base were prepared and fired. Then the PZT with screen printed gold electrodes was chemically laminated to the surface of the LTCC plate, fired and cut into individual beams as presented in Fig. 36a. Additional conductive paths were screen printed as shown in Fig. 36a. Then both the elements were joined using a sealing glass to form the complete device presented in Fig. 36b. Finally the PZT transducers were poled at elevated temperature. The devices were characterized in oscillator mode. The sensitivity was determined by applying a known mass of water to the beaker placed on the cantilever beam, with specified step. The results are presented in Fig. 37, where a series for increasing and decreasing load are presented. The approximated sensitivity was equal to $-11 \mathrm{~Hz} / \mathrm{mN}$. The device exhibits a strong temperature dependence of the oscillation frequency of about $-1.5 \mathrm{kHz} /{ }^{\circ} \mathrm{C}$, hence thermal compensation is necessary.

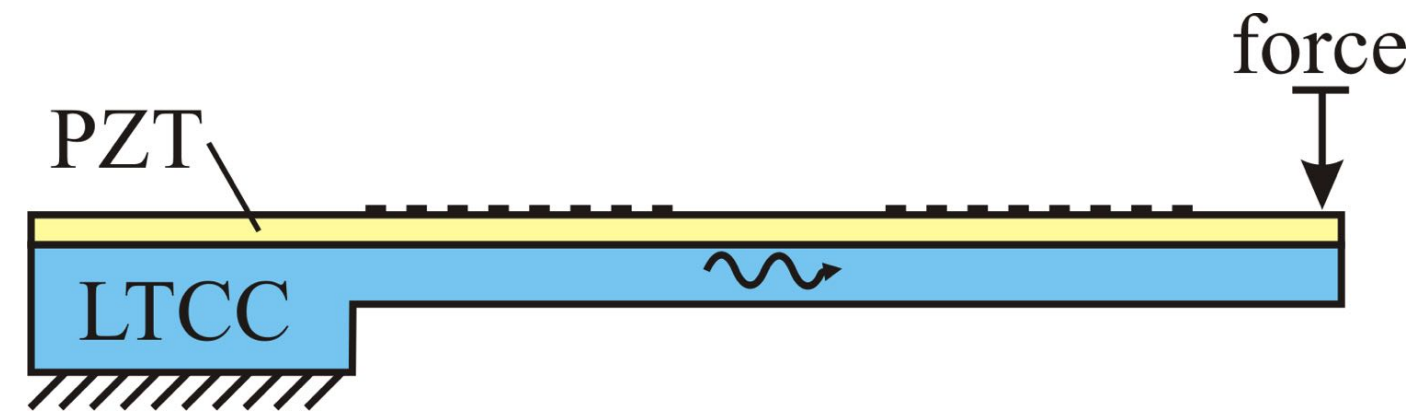

Fig. 35. Concept of the cantilever type force sensor utilizing ultrasonic waves 
a)
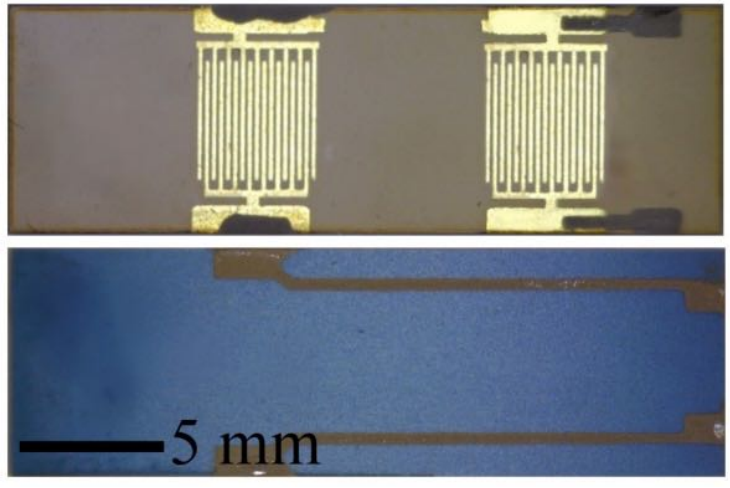

b)

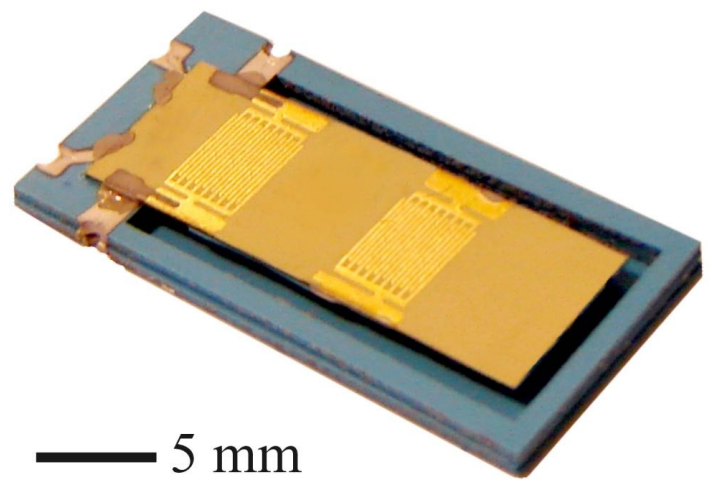

Fig. 36. The sensor beam: a) top and bottom metallization, b) fixed to the base

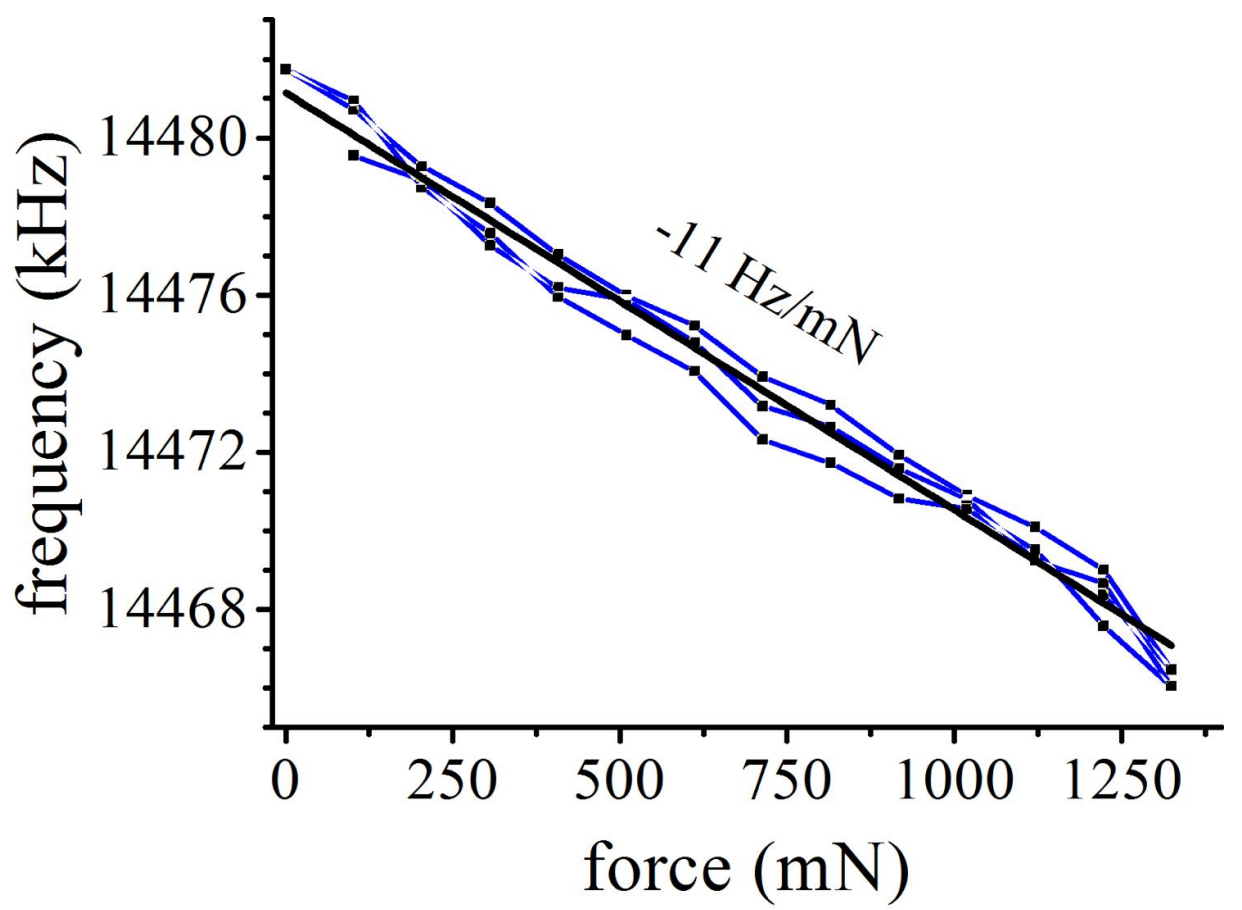

Fig. 37. Three measurement series and sensitivity approximation

\subsection{Integrated flow/pressure/temperature sensor}

Following the successful realization of SMT pressure and flow sensors, both devices were combined into a fully-integrated compressed-air diagnostics sensor for compressed air, with three outputs: pressure, flow (anemometric only) and temperature. The resulting device, shown in Fig. 39, comprises all functions within a 5-layer LTCC structure (Fig. 39). Both, pressure and flow characterization yielded results essentially equivalent to that of the individual sensors [64, 117, 144], with two aspects being important:

1) The pressure sensor must be thermally decoupled from the heat generated by the flow sensor, and mechanically decoupled from the mounting stresses, which is why it lies at one end of the device.

2) Efficient evacuation of the flow sensor heat must be provided for, which is accomplished here using a large mounting pad (Fig. 38). This issue may be mitigated in the future by improving the sensor design and electronics [144]. 


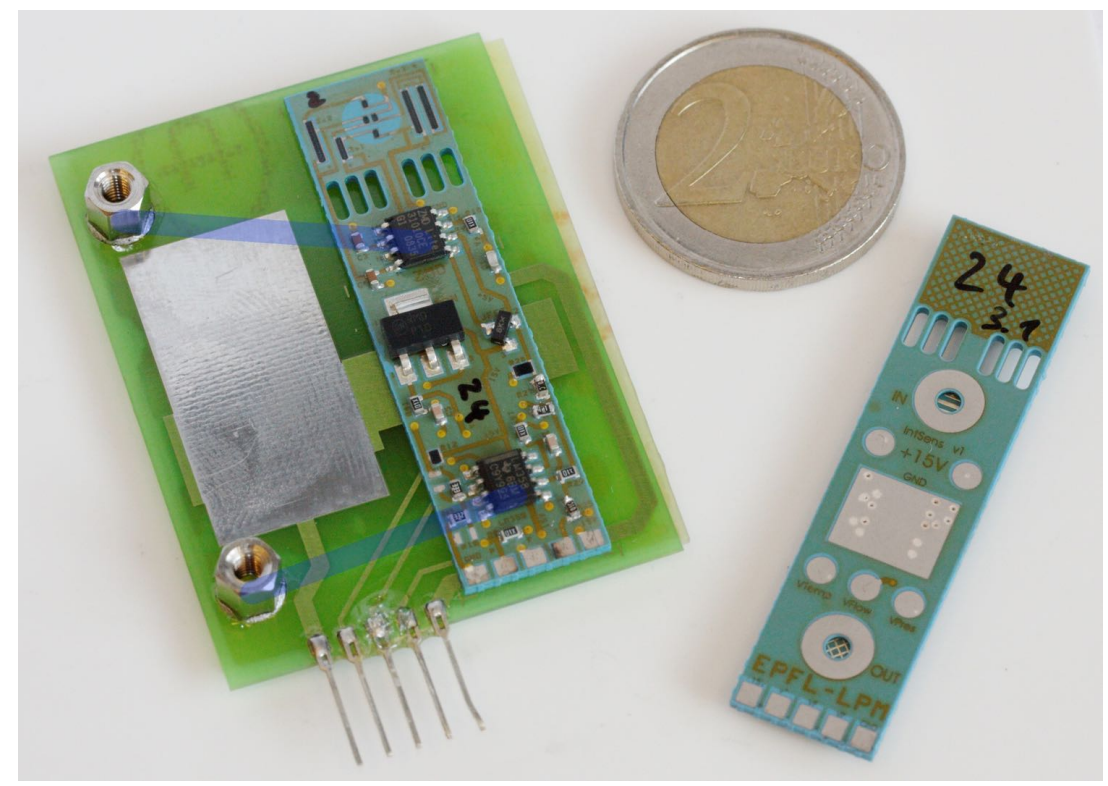

Fig. 38. Integrated pressure-flow-temperature compressed-air diagnostics sensor, compared with 2-euro coin. Left: top side, device mounted on a demo PCB. Right: bottom side, showing the solder pads for both electrical, thermal and fluidic connections. Reprinted from [64].

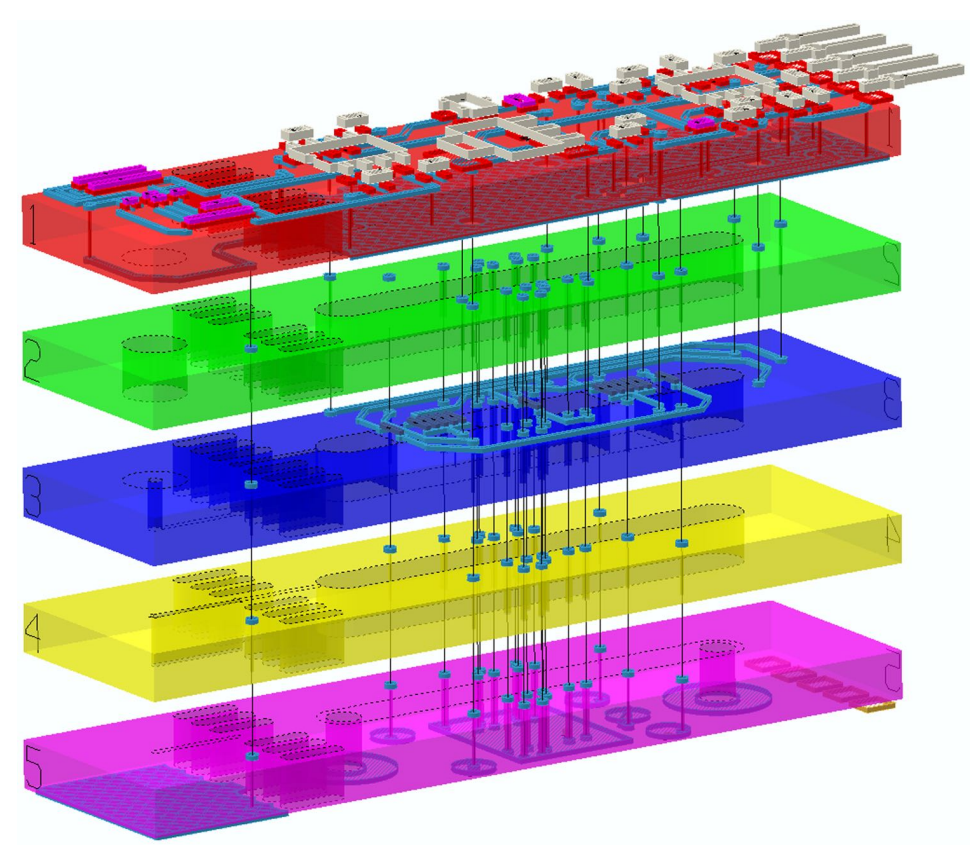

Fig. 39. 3D view of 5-layer structure of integrated pressure-flow-temperature compressed-air diagnostics sensor. Reprinted from [64].

\section{Conclusions}

The potential of Low Temperature Co-fired Ceramics in the field of ceramic sensors was precisely presented in the frame of this paper. Various physical quantity LTCC sensors were presented from the technology and properties point of views. The possibility of integration of various presented sensors into one ceramic module leads to integrated multisensor platforms. Such platforms will be the next milestone of the development of modern sensors. 


\section{References}

[1] L. Golonka, Technology and applications of low temperature cofired ceramic (LTCC) based sensors and microsystems, Bull. Polish Acad. Sci. Tech. Sci. 54 (2006) 221-231.

[2] M. R. Gongora-Rubio, P. Espinoza-Vallejos, L. Sola-Laguna, J.J. Santiago-Aviles, Overview of low temperature co-fired ceramics tape technology for meso-system technology (MsST), Sensors and Actuators A: Physical 89 (2001) 222-241.

[3] X. Wang, A. Stelzer, A 79-GHz LTCC RF-Frontend for Short-Range Applications, IEEE MTT-S International Microwave Symposium Digest (2011) 1-4.

[4] Y. J. Ko, J. Y. Park, J. H. Ryu, K. H. Lee, J. U. Bu, A Miniaturized LTCC Multi-layered Front-end Module for Dual Band WLAN (802.1 la/b/g) Applications, IEEE MTT-S International Microwave Symposium Digest 2 (2004) 563-566.

[5] G. E. Ponchak, D. Chun, J. G. Yook, L. P. B.Katehi, The Use of Metal Filled Via Holes for Improving Isolation in LTCC RF and Wireless Multichip Packages, IEEE Transactions on Advanced Packaging 23 (2000) 88-99.

[6] K. L. Wu, R. Zhang, M. Ehlert, D.G. Fang, An Explicit Knowledge-Embedded Space Mapping Technique and Its Application to Optimization of LTCC RF Passive Circuits, IEEE Transactions on Components and Packaging Technologies 26 (2003) 399-406.

[7] D. Thomas, P. Abhilash, M.T. Sebastian, Casting and characterization of LiMgPO 4 glass free LTCC tape for microwave applications, Journal of the European Ceramic Society 33 (2013) 87-93.

[8] E. Horvath, G. Henap, G. Harsanyi, Finite element modeling of channel sag in LTCC, Microelectronics International 29.3 (2012) 145-152.

[9] A. Roosen, New lamination technique to join ceramic green tapes for the manufacturing of multilayer devices, Journal of the European Ceramic Society 21 (2001) 1993-1996.

[10] S. Nishigaki, J. Fukuta, Low-temperature, cofireable, multilayered ceramics bearing pure- Ag conductors and their sintering behavior, Ceramic Substrates and Packages for Electronic Applications, Advances in Ceramics 26 (1989) 199-215.

[11] J. Zhou, Towards rational design of low-temperature co-fired ceramic (LTCC) materials, Journal of Advanced Ceramics 1 (2012) 89-99.

[12] L. Golonka, P. Bembnowicz, D. Jurków, K. Malecha, H. Roguszczak, R. Tadaszak, Low temperature co-fired ceramics (LTCC) microsystems, Optica Applicata 41 (2011) 383-388.

[13] M. Hrovat, D. Belavič, A. Benčan, J. Bernard, J. Holc, J. Cilenšek, W. Smetana, H. Homolka, R. Reicher, L. Golonka, A. Dziedzic, J. Kita, Thick-film resistors on various substrates as sensing elements for strain-gauge applications, Sensors and Actuators A: Physical 107 (2003) 261-272.

[14] M. Hrovat, D. Belavič, J. Kita, J. Cilenšek, L. Golonka, A. Dziedzic, Thick-film temperature sensors on alumina and LTCC substrates, Journal of the European Ceramic Society 25 (2005) 3443-3450.

[15] H. Bartsch, T. Geiling, J. Müller, A LTCC low-loss inductive proximity sensor for harsh environments, Sensors and Actuators A: Physical 175 (2012) 28-34.

[16] C. Li, Q. Tan, W. Zhang, C. Xue, Y. Li, J. Xiong, Microfabrication of a Novel Ceramic Pressure Sensor with High Sensitivity Based on Low-Temperature Co-Fired Ceramic (LTCC) Technology, Micromachines 5 (2014) 396-407.

[17] G. J. Radosavljevic, L. D. Zivanov, W. Smetana, A. M. Maric, M. Unger, L. F. Nad, A wireless embedded resonant pressure sensor fabricated in the standard LTCC technology. IEEE Sens. J. 9 (2009) 1956-1962.

[18] J. Xiong, Y. Li, Y. Hong, B. Zhang, T. Cui, Q. Tan, S. Zheng, T. Liang, Wireless LTCC- based capacitive pressure sensor for harsh environment. Sensors and Actuators A: Physical 197 (2013) 30-37.

[19] S. Slosarcik, J. Bansky, M. Dovica, M. Tkac, Un - conventional Application of Low Temperature Cofired Ceramics for (Under-) Pressure Sensors, J. Electrical Engineering 48 (1997), 9-10

[20] U. Partsch, C. Lenz, S. Ziesche, C. Lohrberg, H. Neubert, T. Maeder, LTCC-Based Sensors for Mechanical Quantities, Journal of Microelectronics, Electronic Components and Materials 42 (2012) 260-271.

[21] H. Neubert, U. Partsch, D. Fleischer, M. Gruchow, A. Kamusella, T. Pham, Thick film accelerometers in LTCC-technology-design optimization, fabrication, and characterization, in: Proceedings of Ceramic Interconnect and Ceramic Microsystems Technologies Conference, Munich, Germany, 2008.

[22] M. Gongora-Rubio, L. M. Sola-Laguna, P. J. Moffett, J. J. Santiago-Avilés, The utilization of low temperature co-fired ceramics (LTCC-ML) technology for meso-scale EMS, a simple thermistor based flow sensor. Sensors and Actuators A: Physical, 73 (1999) 215-221.

[23] W. Smetana, M. Unger, Design and characterization of a humidity sensor realized in LTCC-technology. Microsyst Technol. 14 (2008) 979-87.

[24] M. Maksimović, G. M. Stojanović, M. Radovanović, M. Malešev, V. Radonjanin, G. Radosavljević, W. Smetana, Application of a LTCC sensor for measuring moisture content of building materials, Construction and Building Materials 26 (2012) 327-333. 
[25] P. Bembnowicz, D. Nowakowska, L. Golonka, Integrated LTCC-glass microreactor and $\mu$ TAS with thermal stabilization for biological application. on: Proceeding of Microelectronics and Packaging Conference, Rimini, Italy, 2009, pp. 1-4.

[26] T. Welker, T. Geiling, H. Bartsch, J. Müller, Design and Fabrication of Transparent and Gas-Tight Optical Windows in Low-Temperature Co-Fired Ceramics, International Journal of Applied Ceramic Technology 10 (2013) 405-412.

[27] K. Malecha, E. Remiszewska, D. G. Pijanowska, Surface modification of low and high temperature co-fired ceramics for enzymatic microreactor fabrication, Sensors and Actuators B: Chemical 190 (2014) 873-880.

[28] M. J. Czok, R. J. Tadaszak, P. I. Bembnowicz, L. J. Golonka, LTCC based chip for monitoring in biological applications, Sensors and Actuators B: Chemical 189 (2013) 118- 122.

[29] K. Malecha, I. Gancarz, L.J. Golonka, A PDMS/LTCC bonding technique for microfluidic application, Journal of Micromechanics and Microengineering 19 (2009) 105016.

[30] M. Goldbach, H. Axthlem, M. Keusgen, LTCC-based microchips for the electrochemical detection of phenolic compounds. Sensors and Actuators B: Chemical 120 (2006) 346-351.

[31] A. Vasudev, A. Kaushik, K. Jones, S. Bhansali, Prospects of low temperature co-fired ceramic (LTCC) based microfluidic systems for point-of-care biosensing and environmental sensing, Microfluidics and nanofluidics 14 (2013) 683-702.

[32] N. C. Pesquero, M. R. Gongora-Rubio, H. Yamanaka, A novel LTCC electrochemical cell construction and characterization: a detection compartment for portable devices, Analyst 138 (2013) 4298-4304.

[33] P. Bembnowicz, L. J. Golonka, LTCC microreactor with thermal stabilization, in: Proceedings of 31st International Spring Seminar on Electronics Technology, Budapest, Hungary, 2008, pp. 276-279.

[34] S. Achmann, M. Hämmerle, J. Kita, R. Moos, Miniaturized low temperature co-fired ceramics (LTCC) biosensor for amperometric gas sensing, Sensors and Actuators B: Chemical 135 (2008) 89-95.

[35] J. Kulawik, D. Szwagierczak, B. Synkiewicz, Tape casting and properties of Pr2O3-doped ZnO multilayer varistors, Microelectronics International 31 (2014) 163-168.

[36] P. Abhilash, D. Thomas, K. P. Surendran, M. T. Sebastian, Facile Synthesis of "Quench-Free Glass" and Ceramic-Glass Composite for LTCC Applications, Journal of the American Ceramic Society 96 (2013) 15331537.

[37] L. Tang, J. Wang, J. Zhai, Low-Temperature Sintering of Ba0. 5Sr0. 5TiO3-SrMoO4 Dielectric Tunable Composite Ceramics for LTCC Applications, Journal of electronic materials 42 (2013) 2542-2548.

[38] J. Kulawik, D. Szwagierczak, Properties of multilayer NTC perovskite thermistors prepared by tape casting, lamination and cofiring, Key Engineering Materials 605 (2014) 507-510.

[39] J. Luo, R. E. Eitel, A Biocompatible Low Temperature Co-fired Ceramic Substrate for Biosensors, International Journal of Applied Ceramic Technology 11 (2014)436-442.

[40] G. Wang, E.C. Folk, F. Barlow, A. Elshabini, Fabrication of microvias for multilayer LTCC substrates, IEEE Transactions on Electronics Packaging Manufacturing 29 (2006) 32- 41.

[41] F. Barlow, J. Wood, A. Elshabini, E.F. Stephens, R. Feeler, G.Kemner, J.Junghans, Fabrication of precise fluidic structures in LTCC, International Journal of Applied Ceramic Technology 6 (2009) 18-23.

[42] S. Rhim, S. Shin, B. Jooi S. Oh, Burr formation during micro via-hole punching process of ceramic and PET double layer sheet, International Journal of Advance Manufacturing Technology 30 (2006) 227-232.

[43] G. Hagen, L. Rebenklau, Fabrication of Smallest Vias in LTCC Tape, in: Proceedings of Electronics System Integration Technology Conference, Dresden, Germany, 2006.

[44] J. Vanek, I. Szendiuch, W. Smetana, M. Unger, Performance of laser machined and metallized via holes in LTCC tape materials, in: Proceedings of 31 st International Spring Seminar on Electronics Technology, Budapest, Hungary, 2008, pp. 540-544.

[45] M. F. Shafique, K. Saeed, D. P. Steenson, I. D. Robertson, Laser prototyping of microwave circuits in LTCC technology, IEEE Transactions on Microwave Theory and Techniques 57 (2009) 3254-3261.

[46] K. M. Nowak, H. J. Baker, D.R. Hall, "Cold" CO2 laser ablation of green-state LTCC- experimental verification of improved model and comparison of various LTCC materials, Applied Physics A: Materials Science \& Processing 103 (2010) 1033-1046.

[47] W. Yung, J. Zhu, Studies on laser ablation of low temperature co-fired ceramics (LTCC), Microelectronics International 24 (2007) 27-33.

[48] J. Zhu, W. K. Yung, Studies on laser ablation of low temperature co-fired ceramics (LTCC), The International Journal of Advanced Manufacturing Technology 42 (2009) 696- 702.

[49] K. M. Nowak, H. J. Baker, D. R. Hall, A model for "cold" laser ablation of green state ceramic materials, Applied Physics A 91 (2008) 341-348.

[50] D. Jurków, L. Golonka, Application of design of the experiment in preliminary investigations on the end milling of Low Temperature Co-fired Ceramics, International Journal of Applied Ceramic Technology 10 (2013) 671-681.

[51] X. Shan, Y. C. Soh, C. W. P. Shi, C. K. Tay, K.M. Chua, C.W. Lu, Large-area patterning of multilayered green ceramic substrates using micro roller embossing, Journal of Micromechanics and Microengineering 18 (2008) 065007. 
[52] H. Bartsch, A. Albrecht, M. Hoffmann, J. Müller, Microforming process for embossing of LTCC tapes, Journal of Micromechanics and Microengineering 22 (2012) 015004.

[53] X. Shan, Y. C. Lam, C. H. Chua, S. H. Ling, C. W. Lu, Experimental study of influential process parameters in hot embossing for micropattern formation on low temperature cofirable ceramic green substrates, Journal of Vacuum Science \& Technology B 27 (2009) 1437-1441.

[54] X. Shan, H.P. Maw, S.H. Ling, Y.C. Lam, Study on micro hot embossing of low temperature co-firable ceramic green substrates, Microsystem technologies 15 (2009) 1225- 1232.

[55] Y.H. Park, C.R. Cho, I.T. Kim, M.W. Lee, K.T. Hwang, J.D. Yu, J.D. Mun, Fabrication of $165 \mu$ m Piched PDP Back Panel Based on LTCC-M Technology, SID Symposium Digest of Technical Papers 31 (2000) 478-481.

[56] H. Bartsch de Torres, R. Gade, A. Albrecht, M. Hoffmann, Systematic characterisation of embossing processes for LTCC tapes, Journal of Microelectronics and Electronic Packaging 5 (2008) 142-149.

[57] M. Ihle, U. Partsch, S. Mosch, Aerosol printed co- and post-fired functional films for LTCC-multilayer components, in: Proceedings of 8th International Conference on Ceramic Interconnect and Ceramic Microsystems Technologies (CICMT), Erfurt, Germany, 2012, pp. 71-76.

[58] J. Sitek, K. Futera, D. Belavič, M.S. Zarnik, M. Kościelski, K. Bukat, K. Janeczek, An investigation of the conductive lines quality deposited by inkjet printing on different substrates, in: Proceedings of IMAPS - IEEE CPMT Poland Conference, Gdansk-Sobieszewo, Poland, 2011, pp. 307-310.

[59] T. Maeder, C. Jacq, Y. Fournier, P. Ryser, Formulation and processing of screen-printing vehicles for sacrificial layers on thick-film and LTCC substrates, in: Proceedings of XXXII International Conference of IMAPS Poland Chapter, Pułtusk, Poland, 2008.

[60] M. Prudenziati, Pastes, inks and slurries, in: M. Prudenziati (Eds.), Handbook of Sensors and Actuators vol. 1: Thick film sensors, Elsevier, 1994, pp. 113-124.

[61] J.J. Felten, Compositions containing diethylene glycol ether, USA patent US4070200. 1978.

[62] K. Malecha, T. Maeder, C. Jacq, P. Ryser, Structuration of the low temperature co-fired ceramics (LTCC) using novel sacrificial graphite paste with PVA-propylene glycol-glycerol- water vehicle, Microelectronics Reliability 51 (2011) 805-811.

[63] K. Malecha, T. Maeder, C. Jacq, Fabrication of membranes and microchannels in low-temperature co-fired ceramic (LTCC) substrate using novel water-based sacrificial carbon pastes, Journal of the European Ceramic Society 32 (2012) 3277-3286.

[64] Y. Fournier, T. Maeder, G. Boutinard Rouelle, A. Barras, N. Craquelin, P. Ryser, Integrated LTCC pressure / flow / temperature multisensor for compressed air diagnostics, Sensors 10 (2010) 11156-11173.

[65] C.S. His, D.P. Chen, P.M. Shieh, S.L. Pu, Processing of LTCC with embedded RuO2- based resistors, Materials Chemistry and Physics 78 (2002) 67-72.

[66] D. Belavič, M. Hrovat, J. Kita, J. Holc, J. Cilenšek, L.J. Golonka, A. Dziedzic, Evaluation of compatibility of thick-film PTC thermistors and LTCC structures, Microelectronics Reliability 45 (2005) 1924-1929.

[67] H. Birol, T. Maeder, C. Jacq, P. Ryser, Investigation of interactions between co-fired LTCC components, Journal of the European Ceramic Society 25 (2005) 2065-2069.

[68] H. Birol, T. Maeder, P. Ryser, Modification of thick-film conductors used in IP technology for reduction of warpage during co-firing of LTCC (low temperature co-fired ceramic) modules, Key Engineering Materials, High Performance Ceramics IV 336-338 (2007) 746-749.

[69] E. Horváth, Á. Török, G. Harsányi. Design and application of low temperature co-fired ceramic substrates for sensors in road vehicles, Transport 28 (2013) 81-88.

[70] D. Jurków, M. Dorczyński, The Comparison of Sheet Resistances of Screen-and Stencil-Printed Resistors, International Journal of Applied Ceramic Technology. (2014) DOI: 10.1111/ijac. 12286.

[71] Datasheet, „Stainless Steel Screen Printing Meshes”, BOPP SD, access online, www.bopp.ch/Bopp2012/media/boppLibrary/DownloadCenter/English/brochures/Bopp_SD_Broschure_e_2013.pdf (access 12.09.2014).

[72] D. Schwanke, J. Pohlner, A. Wonisch, T. Kraft, J. Geng, Enhancement of Fine Line Print Resolution due to Coating of Screen Fabrics, Journal of Microelectronics and Electronic Packaging 6 (2009) 13-19.

[73] E. Horvath, G. Harsanyi, G. Henap, A. Torok, Mechanical modelling and life cycle optimisation of screen printing, Journal of Theoretical and Applied Mechanics 50 (2012) 1025-1036.

[74] S.B. Rane, T. Seth, G.J. Phatak, D. Amalnerkar, M. Ghatpande, Effect of inorganic binders on the properties of silver thick films, Journal of Materials Science: Materials in Electronics 15 (2004) 103-106.

[75] M.H. Tsai, H.H. Chou, W.S. Hwang, P.H. Hsieh, Fabrication of conductive patterns by inkjet printing of silver nano-suspension, in: Proceedings of 4th International Conference on Ceramic Interconnect and Ceramic Microsystems Technologies (CICMT), Munich, Germany 2008, pp. 660-672.

[76] U. Currle, Determination of the stability of low viscous particle inks, in: Proceedings of 8th International Conference on Ceramic Interconnect and Ceramic Microsystems Technologies (CICMT), Erfurt, Germany, 2012, pp. 652-659.

[77] G. Trefalt, M. Kosec, D. Kuščer, G. Stavber, B. Malič, Ink-jet printing of TiO2 suspensions, In Proceedings of 7th International Conference on Ceramic Interconnect and Ceramic Microsystems Technologies (CICMT), San Diego, USA, 2011, pp. 247-254. 
[78] B.J. de Gans, L. Xue, U.S. Agarwal, U.S. Schubert, Ink-jet printing of linear and star polymers, Macromolecular Rapid Communications 26 (2005) 310-314.

[79] A. Kain, C. Mueller, H. Reinecke, High aspect ratio- and 3D- printing of freestanding sophisticated structures, Procedia Chemistry 1 (2009) 750-753.

[80] K. Nowak, R. Tadaszak, T. Ryznar, L. Wozniak, A. Lukowiak, L. Golonka, S. Patela, Sol- gel-based optical waveguides on LTCC substrates. In proceedings of 31st International Spring Seminar on Electronics Technology (2008) 518-522.

[81] L. Golonka, P. Bembnowicz, D. Jurkow, K. Malecha, H. Roguszczak, R. Tadaszak, Low temperature co-fired ceramics (LTCC) microsystems, Optica Applicata 41 (2011) 383-388.

[82] S. Wang, D. Zhou, Z. Hou, Lamination of Green Ceramic Tapes by Applying Pressures Directly at Ambient Temperature, Materials and Manufacturing Processes. (2014).

[83] E. Horváth, G. Harsányi, Optimization of Fluidic Microchannel Manufacturing Processes in Low Temperature Co-Fired Ceramic Substrates, Periodica Polytechnika - Electrical Engineering 54 (2010) 79-86

[84] Y. Imanaka, Multilayered Low Temperature Cofired Ceramics (LTCC) Technology, Springer, New York, 2005.

[85] D. Jurków, L. Golonka, Low pressure thermo-compressive lamination, Journal of the European Ceramic Society 32 (2012) 2431-2441

[86] H. Birol, T. Maeder, P. Ryser, Application of graphite-based sacrificial layers for fabrication of LTCC (low temperature co-fired ceramics) membranes and micro-channels, Journal of Micromechanics and Microengineering 17 (2007) 50-60

[87] K. A. Peterson, K. D. Patel, C. K. Ho, S. B. Rohde, C. D. Nordquist, C. A. Walker, B. D. Wroblewski, M. Okandan, Novel microsystem applications with new techniques in low temperature co-fired ceramics International, Journal of Applied Ceramic Technology 2 (2005) 345-363.

[88] K. Malecha, D. Jurków, L. Golonka, Comparison of solvent and sacrificial volume material based lamination processes of Low Temperature Co-fired Ceramics (LTCC) Tapes, Journal of Micromechanics and Microengineering 9 (2009) 1-10.

[89] L. E. Khoong, Y. M. Tan, Y. C. Lam, Overview on fabrication of three-dimensional structures in multi-layer ceramic substrate, Journal of the European Ceramic Society 30 (2010) 1973-1987.

[90] M. A. Piwonski, A. Roosen, Low pressure lamination of ceramic green tapes by gluing at room temperature, Journal of the European Ceramic Society 19 (1999) 263-270.

[91] A. Roosen, K. Schindler, Cold low pressure lamination of ceramic green tape, In Proceedings of 1st International Conference and Exhibition on Ceramic Interconnect and Ceramic Microsystem Technologies (2005) 397-403

[92] Z. M. da Rocha, N. Ibañez Garcia, N. A. Oliveira, J. Matos, D. Rosário, M. R. Gongora- Rubio, Low temperature and pressure lamination of LTCC tapes for meso-systems, in: Proceedings IMAPS Conference and Exhibition on Ceramic Interconnect Technology, Denver, USA, 2004.

[93] J. Gurauskis, A. J. Sanchez-Herencia, C. Baudin, Joining green ceramic tapes made from water-based slurries by applying low pressures at ambient temperature, Journal of the European Ceramic Society 25 (2005) 34023411 .

[94] T. Maeder, B. Jiang, F. Vecchio, C. Jacq, P. Ryser, P. Muralt, Lamination of LTCC at low pressure and moderate temperature using screen-printed adhesives, In Proceedings of 8th International Conference on Ceramic Interconnect and Ceramic Microsystems Technologies (CICMT). (2012) 348-352.

[95] N. Suppakarn, H. Ishida, J. D. Cawley, Roles of poly (propylene glycol) during solvent- based lamination of ceramic green tapes, Journal of the American Ceramic Society 84 (2001) 289-294.

[96] D. Jurków, L. Golonka, Cold Chemical Lamination - new bonding technique of LTCC green tapes, International Journal of Applied Ceramic Technology 7 (2010) 814-820.

[97] X. Shan, H.P. Maw, C.W. Lu, Solvent-assisted low pressure room temperature lamination of low temperature cofirable ceramic green tapes for formation of embedded micro channels, Microsystems Technology 16 (2010) 1501-1506.

[98] J.A. Lewis, Binder removal from ceramics, Annual Review of Materials Science 27 (1997) 147-173.

[99] A. Mohanram, G.L. Messing, D.J. Green, Densification and Sintering Viscosity of Low-Temperature CoFired Ceramics, Journal of the American Ceramic Society 88 (2005) 2681-2689.

[100] D. Belavic, M. Hrovat, M.S. Zarnik, J. Holc, M. Kosec, An investigation of thick PZT films for sensor applications: a case study with different electrode materials, Journal of Electroceramics 23 (2009) 1-5.

[101] M. S. Zarnik, D. Belavic, S. Macek, J. Holc, Feasibility study of a thick-film PZT resonant pressure sensor made on a prefired 3D LTCC structure, International Journal of Applied Ceramic Technology 6 (2009) 9-17.

[102] M. S. Zarnik, D. Belavic, S. Macek, Experimental and numerical analyses of thick-film piezoceramics structures for miniaturised sensor and actuators, Microelectronics International 25 (2008) 31-36.

[103] M.S. Zarnik, D. Belavic, H. Uršič, S. Macek, Numerical modelling of ceramic MEMS structures with piezoceramic thick films, Journal of Electroceramics 20 (2008) 3-9. 
[104] D. Belavic, M. Santo Zarnik, M. Hrovat, S. Macek, M. Pavlin, M. Jerlah, J. Holc, S. Drnovsek, J. Cilensek, M. Kosec, Benchmarking different types of thick-film pressure sensors, in: Proceedings of the IMAPS/ACerS 2007, In Proceedings of 3rd International Conference and Exhibition on Ceramic Interconnect and Ceramic Microsystems Technologies (CICMT 2007), Denver, USA, 2007, pp. 278-285.

[105] D. Belavic, M. Santo Zarnik, M. Hrovat, M. Jerlah, S. Macek, J. Holc, S. Drnovšek, J. Cilensek, M. Pavlin, M. Kosec, M. Pizzi, M. Paderi, Resonant, capacitive and piezoresistive thick-film pressure sensors: an evolution, in: invited talk at Piezoelectricity for end users III : POLECER conference, Liberec, Czech Republic, 2005.

[106] M. S. Zarnik, D. Belavic, S. Macek, Evaluation of the constitutive material parameters for the numerical modelling of structures with lead-zirconate-titanate thick films, Sensors and actuators. A, Physical 136 (2007) 618-628.

[107] A. Dabrowski, L. Golonka, High pressure sensor with PZT transducer in LTCC package, Procedia Engineering 87 (2014) 1099-1102.

[108] A. Dabrowski, L. Golonka, LTCC/PZT differential pressure sensor utilizing ultrasonic wave resonator, in: Proceedings of 37th International Spring Seminar on Electronics Technology, Dresden, Germany, 2014.

[109] D. Belavic, M. Hrovat, J. Holc, M. Santo Zarnik. M. Kosec, M. Pavlin, The application of thick-film technology in C-MEMS, Journal Electroceramics 19 (2007) 363-368.

[110] M. S. Zarnik, D. Belavic, V. Sedlakova, J. Sikula, M. Kopecky, P. Sedlak, J. Majzner, Comparison of the intrinsic characteristics of LTCC and silicon pressure sensors by means of $1 /$ f noise measurements, Radioengineering 22 (2013) 227-232.

[111] V. Sedlakova, J. Majzner, P. Sedlak, M. Kopecky, J. Sikula, M.S. Zarnik, D. Belavic, M. Hrovat, Evaluation of piezoresistive ceramic pressure sensors using noise measurements, Informacije MIDEM 42 (2012) 109-114.

[112] M.S. Zarnik, D. Belavic, S. Macek, The warm-up and offset stability of a low-pressure piezoresistive ceramic pressure sensor, Sensors and actuators A, Physical. 158 (2010) 198- 206.

[113] M. S. Zarnik, D. Belavič, Stability of a Piezoresistive Ceramic Pressure Sensor Made With LTCC Technology, in: Proceedings of IMAPS/ACerS Conf (CICMT), Erfurt, Germany, 2012.

[114] M. S. Zarnik, D. Belavic, The effect of humidity on the stability of LTCC pressure sensors, Metrologia i Systemy Pomiarowe 19 (2012) 133-140.

[115] M. S. Zarnik, V. Sedlakova, D. Belavic, J. Sikula, J. Majzner, P. Sedlak, Estimation of the long-term stability of piezoresistive LTCC pressure sensors by means of low-frequency noise measurements, Sensors and actuators A, Physical 199 (2013) 334-343.

[116] M. S. Zarnik, D. Belavic, Study of LTCC-based pressure sensors in water, Sensors and actuators A, Physical 220 (2014) 45-52.

[117] Y. Fournier, A. Barras, G. Boutinard Rouelle, T. Maeder, P. Ryser, SMD pressure and flow sensors for industrial compressed air in LTCC technology, In: Proceedings of 17th European Microelectronics \& Packaging Conference (EMPC), Rimini, Italy, 2009.

[118] D. Belavic, M. Santo Zarnik, C. Marghescu, C. Ionescu, P. Svasta, M. Hrovat, S. Macek, I. Lipušček, S. Kocjan, Design of a capacitive LTCC-based pressure sensor, in: Proceedings of 15th International Symposium for Design and Technology of Electronics Packages, Gyula, Hungary, 2009, pp. 31-36.

[119] D. Belavic, M. Santo Zarnik, M. Hrovat, S. Macek, M. Kosec, Temperature behaviour of capacitive pressure sensor fabricated with LTCC technology, Informacije MIDEM 38 (2008) 191-196.

[120] M. S. Zarnik, D. Belavic, S. Macek, Design study for a capacitive ceramic pressure sensor, Microelectronics International 28 (2011) 31-35.

[121] M.S. Zarnik, M. Možek, S. Macek, D. Belavic, An LTCC-based capacitive pressure sensor with a digital output, Informacije MIDEM 40 (2010) 74-81.

[122] M. S. Zarnik, D. Belavic, An experimental and numerical study of the humidity effect on the stability of a capacitive ceramic pressure sensor, Radioengineering 21 (2012) 201-206.

[123] D. Jurków, A. Dąbrowski, L. Golonka, T. Zawada, Preliminary Model and Technology of Piezoelectric Low Temperature Co-fired Ceramic (LTCC) Uniaxial Accelerometer, Int. J. Appl. Ceram. Technol. 10 (2013) 395404.

[124] D. Jurków, Technology and properties of integrated LTCC sensors, in: J. Kacprzyk (Eds.), Innowacyjne rozwiązania w obszarze automatyki, robotyki i pomiarów, PIAP, Warsaw, 2013, pp. 9-18.

[125] D. Jurków, Three axial Low Temperature Cofired Ceramic accelerometer, Microelectronics International 30 (2013) 125-133.

[126] A. Dabrowski, K. Elkjaer, L. Borregaard, T. Zawada, L. Golonka, LTCC/PZT accelerometer in SMD package, Microelectronics International 31 (2014) 186-192.

[127] D. Jurków, L. Golonka, H. Roguszczak, LTCC gas flow sensor, in: Proceedings of International Microelectronics and Packaging Society Conference, Chapter Poland, Krasiczyn, Poland, 2007, pp. $279-282$.

[128] D. Jurków, L. Golonka, Integrated LTCC gas flow sensor with measuring device, in: Proceedings of International Conference and Exhibition on Ceramic Interconnect and Ceramic Microsystem Technologies, Munich, Germany, 2008. 
[129] D. Jurków, K. Malecha, L. Golonka, Three element gas flow sensor integrated with Low Temperature Cofired Ceramic (LTCC) Module, in: Proceedings of International Conference Mixed Design of Integrated Circuits and Systems, Łódź, Poland, 2009, pp. 93-96.

[130] H. Bartsch de Torres, C. Rensch, M. Fischer, A. Schober, M. Hoffmann, J. Müller, Thick film flow sensor for biological microsystems, Sensors and Actuators A: Physical 160 (2010) 109-115.

[131] S. D. Roach, Designing and building an eddy current position sensor, Sensors Online, 1998, available online at: http://www.sensorsmag.com/sensors/electric-magnetic/designing- and-building-eddy-current-position-sensor772 (accessed at 22.01.2015).

[132] M.R. Gongora-Rubio, L.M. Sola-Laguna, M. Smith, J.J. Santiago Aviles: LTCC technology multilayer eddy current proximity sensor for harsh environments, in: Proceedings of 32nd International Symposium on Microelectronics, 1999, pp. 676-681

[133] Y. Lai, Eddy current displacement sensor with LTCC technology. PhD thesis, Freiburg (Breisgau), (2005) URN: urn:nbn:de:bsz:25-opus-19152

[134] R. Perrone, H. Bartsch de Torres, M. Hoffmann, M. Mach, J. Müller, Miniaturized Embossed Low Resistance Fine Line Coils in LTCC, Journal of Microelectronics and Electronic Packaging 6 (2009) 42-48.

[135] O. Lambercy, L. Dovat, H. Yun, S.K. Wee, C.W. Kuah, K.S. Chua, R. Gassert, T.E. Milner, C.L. Teo, E. Burdet, Effects of a robot-assisted training of grasp and pronation/supination in chronic stroke: a pilot study, Journal of Neuro Engineering and Rehabilitation 8 (2013) 63.

[136] R. Zimmermann, L. Marchal Crespo, J. Edelmann, O. Lambercy, M.C. Fluet, R. Riener, M. Wolf, R. Gassert, Detection of motor execution using a hybrid fNIRS-biosignal BCI: a feasibility study, Journal of Neuro Engineering and Rehabilitation 10 (2013).

[137] T. Maeder, V. Fahrny, S. Stauss, G. Corradini, P. Ryser, Design and characterisation of low-cost thick-film piezoresistive force sensors for the $100 \mathrm{mN}$ to $100 \mathrm{~N}$ range, in: Proceedings of XXIX International Conference of IMAPS Poland, Koszalin-Darłówko, Poland, 2005, pp. 429-434.

[138] T. Maeder, I. Saglini, G. Corradini, P. Ryser, Low-cost thick-film force sensors for the $100 \mathrm{~N}$ force range, in: Proceedings of XXX International Conference of IMAPS Poland Chapter. Cracow, Poland, 2006, pp. 193-196.

[139] H. Birol, T. Maeder, I. Nadzeyka, M. Boers, P. Ryser, Fabrication of a millinewton force sensor using low temperature co-fired ceramic (LTCC) technology, Sensors and Actuators A 134 (2007) 334-338.

[140] T. Maeder, C. Jacq, P. Ryser, Long-term mechanical reliability of ceramic thick-film circuits and mechanical sensors under static load, Sensors and Actuators A 186 (2012) 210- 218.

[141] T. Maeder, C. Jacq, H. Birol, P. Ryser, High-strength ceramic substrates for thick-film sensor applications, in: Proceedings of 14th European Microelectronics and Packaging Conference - IMAPS, Friedrichshafen, Germany, 2003, pp. 133-137.

[142] C. Jacq, T. Maeder, E. Haemmerle, N. Craquelin, P. Ryser, Ultra-low pressure sensor for neonatal resuscitator, Sensors and Actuators A 172 (2011) 135-139.

[143] A. Dabrowski, L. J. Golonka, PZT acoustic wave force sensor made in LTCC technology. in: Proceedings on European Microelectronics Packaging Conference (EMPC), Grenoble, France, 2013, pp. 1-5.

[144] T. Maeder, Y. Fournier, J.-B. Coma, N. Craquelin, P. Ryser, Integrated SMD pressure/flow/temperature multisensor for compressed air in LTCC technology: Thermal flow and temperature sensing, Microelectronics Reliability 51 (2011) 1245-1249.

\section{Figure captions}

Fig. 1. Tape casting process principle

Fig. 2. Embossing, a) process flow for embossing of green LTCC tapes, b) major effects on the embossing result for fine line forming

Fig. 3. Effect of plasticiser on PVP-bound sacrificial graphite layer: the stresses in the hard, unplasticised PVP (a) result in cracking of the LTCC tape, while no cracking is observed with glycerol plasticiser (b). Reprinted from [63], with permission from Elsevier (@2012).

Fig. 4. Delamination of LTCC structures (blue) and sacrificial carbon paste (black) during the debinding step (firing interrupted at $520^{\circ} \mathrm{C}$ ), due to a combination of large amounts of PVP binder and high decomposition temperature thereof blocking gases evolved during debinding. Reprinted from [63], with permission from Elsevier (C2012).

Fig. 5. Deformation of fine LTCC bridges of a flow sensor due to dimensional variations of the Ag-Pd conductor (right), an issue mitigated by using thinner and/or narrower conductor tracks (left). Reprinted from [64]. 
Fig. 6. The scheme of the cross-section of the thick-film actuator/sensor structure on the LTCC membrane (Not to scale)

Fig. 7. Piezoelectric resonant pressure sensor a) the prototype, b) the sensor/actuator structure in the oscillator circuit and c) the typical measured characteristic

Fig. 8. Piezoelectric pressure sensor in LTCC package, a) cross section of designed sensor, b) bottom electrode on PZT tape, c) fabricated device

Fig. 9. Results of measurements: a) charge response, b) resonant frequency shift

Fig. 10. Design of differential pressure sensor, a) cross section, b) membrane with IDT transducers, c) completely assembled device

Fig. 11. Results of measurements in oscillator mode: a) static, b) dynamic measurement

Fig 12. Schematic representation of the sensor (not to scale): a) the cross-section, b) sketch of the top-view and c) the Wheatstone-bridge's connection of the thick-film piezoresistors.

Fig. 13. The 10-kPa pressure sensors tested for long-term stability (made of tape DuPont 951 and thick film resistors DP 2000 series).

Fig. 14. SMT-mounted pressure sensor [117], comprising an integrated pressure membrane (highlighted in green) together with a signal-conditioning chip.

Fig. 15. Pressure sensor [117] on demo PCB: 3D structure (top) and photograph (bottom).

Fig. 16. The principle of the diaphragm-type capacitive pressure sensor

Fig. 17. a) Schematics of the cross-section of the CPS body (not to scale) and b) the prototype with the additional electrode on top and readout electronics realized using AD7746.

Fig. 18. Piezoelectric accelerometer, a) schematic cross-section visualizing a working principle, b) fabricated sensor

Fig. 19.Manufactured LTCC three axial piezoresistive acceleration sensor

Fig. 20. Design of the uniaxial accelerometer with main dimensions (not to scale)

Fig. 21. a) LTCC with formed seismic mass, b) PZT/LTCC cantilever with electrodes and c) joined elements

Fig. 22. Accelerometer soldered to a holder

Fig. 23. Results of measurements: a) sensitivity at $100 \mathrm{~Hz}, \mathrm{~b}$ ) spectrum at $1 \mathrm{~g}$

Fig. 24. LTCC fluid flow sensor, a) single turbine, b) sensor

Fig. 25. Calibration of LTCC turbine based flow sensor, a) measurement setup and working principle, b) calibrating curve

Fig. 26. Three element gas flow sensor, a) schematic diagram of working principle [124], b) measurement setup

Fig. 27. Fabricated three element gas flow sensor

Fig. 28. Principle of a versatile thermal flow sensor [117], with resistors for both calorimetric and anemometric sensing principles.

Fig. 29. Flow sensor [117] 3D structure (left) and photograph of the bottom three layers (right), showing the inner sensing layer with the resistive bridges.

Fig. 30. Calorimetric (Vcal) and anemometric (Pheater) flow sensor output, as a function of flow [117].

Fig. 31. Eddy current sensor, a) measuring principle, b) basic dimensions of the sensor

Fig. 32. Coils comparison, a) cross section of a screen printed conductor path, b) cross section of an embossed conductor path, c) comparison of the sensitivity for a sensor with printed coil and embossed coil.

Fig. 33. Two force sensors with alumina base and LTCC cantilever (blue), with the top device being oriented so that the gap between cantilever and base is visible. 
Fig. 34. Layout (top) and image (bottom) of the bottom face of the LTCC cantilever (wires running within the device and essentially blank top face not shown). Inset: detail of the differential cut-out of both LTCC layers, showing a larger area for the top (T) than for the bottom (B) tape.

Fig. 35. Concept of the cantilever type force sensor utilizing ultrasonic waves

Fig. 36. The sensor beam: a) top and bottom metallization, b) fixed to the base

Fig. 37. Three measurement series and sensitivity approximation

Fig. 38. Integrated pressure-flow-temperature compressed-air diagnostics sensor, compared with 2-euro coin. Left: top side, device mounted on a demo PCB. Right: bottom side, showing the solder pads for both electrical, thermal and fluidic connections. Reprinted from [64].

Fig. 39. 3D view of 5-layer structure of integrated pressure-flow-temperature compressed-air diagnostics sensor. Reprinted from [64].

\section{Table captions}

Table 1. The basic parameters of piezoelectric acceleration sensor [124]

Table 2. The basic parameters of LTCC three axial piezoresistive acceleration sensor [124]

Table 3. The parameters of the flow sensor [124]

Table 4. Overview of basic parameters for LTCC eddy current sensor coils (geometric parameter see Fig. 31b)

\section{Biographies}

Dominik Jurków - (www.ltcc.org.pl) received his MSc and PhD in
Electronics from Wroclaw University of Technology (Poland) in 2008 and
2012, respectively. He has years of experience in LTCC integrated
passives, sensors, actuators and microsystems research which is document
by dozen publications in journals indexed at JCR list and patents. His PhD
thesis was honored as very good work by ABB Company in 2013, Cracow
(Poland) and awarded as the best thesis by Polish Prime Minister in 2013,
Warsaw (Poland). Recently he is a Head of Research and Development at
VIA Electronic (Germany).




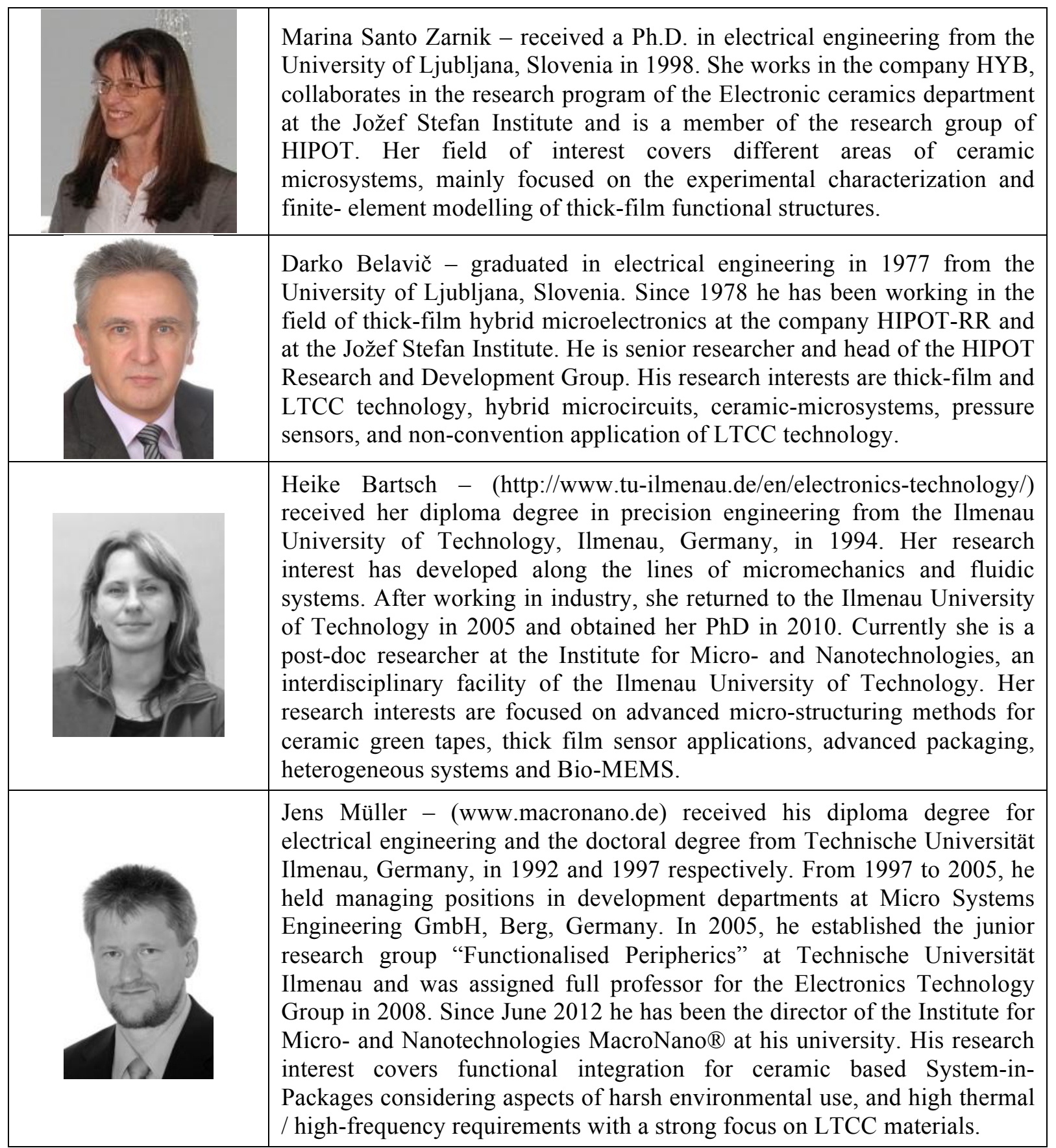

